\title{
Singing in the Key of Life: A Study on Effects of Musical Ear Training After Cochlear Implantation
}

\author{
Bjørn Petersen \\ Aarhus University Hospital and Royal Academy of Music \\ Mads Hansen \\ Aarhus University Hospital and Aarhus University
}

\author{
Malene Vejby Mortensen ${ }^{\dagger}$ \\ Aarhus University Hospital
}

Peter Vuust

Aarhus University Hospital and Royal Academy of Music

\begin{abstract}
This study investigated the effect of a 6-month one-to-one musical ear-training program on the perception of music, speech, and emotional prosody of deaf patients receiving a cochlear implant (CI). Eighteen patients who recently underwent cochlear implantation were assigned to either a musical ear-training group or a control group. The participants in the music group significantly improved in their overall music perception compared with the control group. In particular, their discrimination of timbre, melodic contour, and rhythm improved. Both groups significantly improved in their speech perception; thus, this effect cannot be specifically ascribed to music training. In contrast to the control group, the music group showed an earlier onset of progress in recognition of emotional prosody, whereas end-point performances were comparable. All participants completed the program and showed great enthusiasm for the musical ear training, particularly singing-related activities. If implemented as part of aural/oral rehabilitation therapy, the proposed musical ear-training program could form a valuable complementary method of auditory rehabilitation, and, in the long term, contribute to an improved general quality of life in CI users.
\end{abstract}

Keywords: cochlear implants, music perception, music enjoyment, music training, music testing

Supplemental materials: http://dx.doi.org/10.1037/a0031140.supp

A cochlear implant (CI) is a neural prosthesis that helps deaf people to hear. The implant operates by an external signal processor, which breaks up sound into different frequencies, converts these into electrical signals, and transmits them to an internal receiver through a radio-frequency link. The receiver passes the stimuli onto an implanted electrode array, which stimulates remaining auditory nerve fibers in the cochlea (Loizou, 1999). The auditory nerve is hereby activated, allowing sound signals to reach the brain's auditory system. The clinical impact of the evolution of CIs has been nothing less than extraordinary. With current implant technology and up-to-date sound-processing strategies, the average
CI listener recognizes $>80 \%$ of sentences and approximately $55 \%$ of monosyllabic words, in quiet listening conditions, after 12 months of practice with a unilateral CI; some users even achieve the capability of talking on the phone (Friesen, Shannon, Baskent, \& Wang, 2001; Wilson \& Dorman, 2007). The variability in implant outcome, however, is large, with duration of hearing loss (HL) and residual hearing as important predictors of the result (Cosetti \& Waltzman, 2012; Lee et al., 2007; Summerfield \& Marshall, 1995; Waltzman, Fisher, Niparko, \& Cohen, 1995). With the considerable improvements made in CI technology with regard to speech perception, it is natural that many existing $\mathrm{CI}$
Bjørn Petersen, Center of Functionally Integrative Neuroscience, Aarhus University Hospital, Aarhus, Denmark, and Royal Academy of Music, Aarhus/Aalborg, Denmark; Malene Vejby Mortensen, Department of Otorhinolaryngology, Aarhus University Hospital; Mads Hansen, Center of Functionally Integrative Neuroscience, Aarhus University Hospital, and Department of Psychology and Behavioural Sciences, Aarhus University, Aarhus, Denmark; Peter Vuust, Center of Functionally Integrative Neuroscience, Aarhus University Hospital, and Royal Academy of Music.

The authors thank the individuals who participated in the study. The authors also thank Roberta Hardgrove Hansen and Minna Sandahl for helpful assistance with participant recruitment and provision of clinical data for the participants. This work was supported by grants from the Augustinus Foundation, the Hørslev Foundation, Petra and Niels Nielsen's Memorial Foundation, L.F. Foght's Foundation and The Danish Associa- tion of the Hard of Hearing. Presented, in part, at the 11th International Conference on Cochlear Implants and Other Implantable Auditory Technologies, Stockholm, Sweden, June 30-July 3, 2010.

${ }^{\dagger}$ Malene Vejby Mortensen sadly passed away on August 5, 2011, from leukemia. She was an MD, and ENT-specialist, who contributed greatly to the implementation and completion of this study. A great music lover herself, Mortensen became interested in music and speech perception after cochlear implantation while working on her $\mathrm{PhD}$ thesis titled "Brain Maps of Auditory Processes in Normal Hearing, Postlingual Deafness and Cochlear Implantation," which she defended in 2005.

Photos and brief biographies of each author are available at http:// dx.doi.org/10.1037/a0031140.supp

Correspondence concerning this article should be addressed to Bjørn Petersen, PhD, Royal Academy of Music, Skovgaardsgade 2, 8000 Aarhus C, Denmark. E-mail: bpe@musikkons.dk 
users express hopes of being able to enjoy music. Moreover, because music has played an essential role in many of these patients' cultural and social life before deafness, CI candidates' hope of retrieving music enjoyment is an important reason for choosing this treatment (Gfeller et al., 2000).

For the majority of CI users, however, the music experience is disappointing. Surveys have shown that a majority of adult CI recipients' self-reported levels of music listening and enjoyment are significantly lower after than before implantation (Gfeller et al., 2000; Lassaletta et al., 2007; Looi \& She, 2010; Mirza, Douglas, Lindsey, Hildreth, \& Hawthorne, 2003). This reduced music appreciation is due to a general difficulty with perceiving complex acoustic stimuli, which also includes speech perception in conditions involving background noise or competing talkers. Because of the limited number of available electrodes and the mismatch between the pulse-rate of the electrical impulses and the sound input frequency coupled with the dominance of temporal processing for low-frequency sound, the CI signal is unable to adequately code the spectrum of sound needed to perceive musical pitch and timbre. Furthermore, a range of individual patient variables, such as degree of auditory neuron survival, insertion depth, and placement of the electrodes within the cochlea, often impact the extent to which musical information can be successfully decoded (McDermott, 2004). This is supported by several studies, which conclude that although perception of simple rhythm patterns approaches normal hearing $(\mathrm{NH})$ levels, recognition of melody and timbre is significantly poorer in CI users than in $\mathrm{NH}$ control subjects (Cooper, Tobey, \& Loizou, 2008; Gfeller, Witt, Woodworth, Mehr, \& Knutson, 2002; Gfeller et al., 2005, 2007; Kong, Cruz, Jones, \& Zeng, 2004; Leal et al., 2003; McDermott, 2004; Olszewski, Gfeller, Froman, Stordahl, \& Tomblin, 2005). Nevertheless, some studies indicate that CI recipients in some cases seem to overcome the technological limitations and apparently revive their long-lost music enjoyment through repeated listening (Gfeller \& Lansing, 1991; Gfeller et al., 2005). Such successful music outcome may be associated with factors such as musical background, musical exposure, and residual hearing as suggested in some reports (Gfeller, Olszewski, Turner, Gantz, \& Oleson, 2006; Gfeller et al., 2008; Lassaletta et al., 2008; Mirza et al., 2003). Furthermore, studies involving computer-assisted music training have demonstrated significant improvement of discrimination of melodic contour, musical timbre, and recognition and appraisal of songs (Galvin, Fu, \& Nogaki, 2007; Gfeller, Witt, Stordahl, Mehr, \& Woodworth, 2000; Gfeller et al., 2002b). This indicates that the possibility of overcoming the limitations of the implant and developing improved musical pattern recognition relies on "active" learning efforts (Fu \& Galvin III, 2008). Thus far, no data are at hand concerning the effects of longitudinal one-to-one musical ear training and active music making in adult CI users.

Improved perception of music may have considerable positive implications not only for music enjoyment but also for other aspects of listening. In NH listeners, music training is beneficial for the development of specific auditory skills, such as discrimination of pitch, timing, and timbre, and also essential in language comprehension (Altenmüller, 2008; Koelsch, Schroger, \& Tervaniemi, 1999; Näätänen, Gaillard, \& Mäntysalo, 1978; Näätänen, Tervaniemi, Sussman, Paavilainen, \& Winkler, 2001; Pantev et al., 1998; Vuust et al., 2005). Furthermore, enhanced music abilities may enhance speech perception in noisy surroundings, which relies on pitch cues to separate the target from the background (Parbery-Clark, Skoe, Lam, \& Kraus, 2009; Qin \& Oxenham, 2003), and the ability to identify voice gender and speaker, which largely depends on discrimination of timbral cues (Vongphoe \& Zeng, 2005). Finally, recent brain-imaging studies have shown that complex music tasks activate brain areas associated with language processing (Levitin \& Menon, 2003; Vuust, Roepstorff, Wallentin, Mouridsen, \& Østergaard, 2006; Vuust \& Roepstorff, 2008). Thus, musical training of CI users may be hypothesized to positively influence speech perception.

Because an important function of music is to convey emotion (Juslin \& Laukka, 2003), musical training in particular has been suggested as a way to enhance processing of the emotional aspects of language, which are mediated by loudness, speech rate, and pitch contour. Thompson, Schellenberg, and Husain (2003) found that musically trained $\mathrm{NH}$ participants outperformed untrained participants when extracting prosodic cues in speech, and Besson, Schön, Moreno, Santos, and Magne (2007) found that musical training of 9- to 11-year-old children enhanced their ability to perceive prosodic cues compared with a control group receiving drama lessons. These findings could indicate a potential positive effect of musical ear training also on the emotional processing of speech in CI users.

In summary, the aim of the present study was to develop a one-to-one musical ear-training program, targeted at adult CI users who recently underwent implantation. We hypothesized that weekly one-to-one training, involving active music making and listening exercises, would substantially enhance the musical discrimination skills of the participants, compared with a group of control subjects. We also hypothesized that the possible enhanced discrimination skills could generalize to the linguistic domain and positively affect the CI users' recognition of speech and emotional prosody. To measure the progress of the participants, we developed a music test battery targeted at CI users, which would measure a broad range of music-related perceptual skills objectively and effectively.

\section{Methods}

\section{Ethical Approval}

The study was conducted in accordance with the Helsinki declaration and approved by the research ethics committee of the Central Denmark Region. Informed consent was obtained from all participants.

\section{Participants}

Over the course of 2 years, patients who were approved for implantation were contacted by mail and invited to take part in the research project. From 41 patients, 18 accepted the invitation and were assigned to either a music group (MG: six women, three men, $M_{\text {age }}=46.7$ years, age range: $21-70$ years) or a control group (CG: four women, five men, $M_{\text {age }}=58.6$ years, age range: $45-73$ years), matched according to duration of deafness, use of hearing aid (HA) in the nonimplanted ear, degree of deafness, and availability for the weekly music-training sessions. All participants had received unilateral implants. Five participants (MG 2, MG 8, CG 3, CG 4, and CG 6) had a prelingual profound HL, as indicated by 
Table 1

Clinical and Demographic Data of the 18 Participants Included in the Study

\begin{tabular}{|c|c|c|c|c|c|c|c|c|c|c|}
\hline Participant (gender) & $\begin{array}{l}\text { Age at } \\
\text { project start } \\
\text { (years) }\end{array}$ & $\begin{array}{l}\text { Etiology of } \\
\text { deafness }\end{array}$ & $\begin{array}{l}\text { Side of } \\
\text { implant }\end{array}$ & $\begin{array}{l}\text { Contralateral } \\
\text { use of HA }\end{array}$ & $\begin{array}{c}\text { Onset of } \\
\text { HL } \\
\text { (years) }\end{array}$ & $\begin{array}{l}\text { Duration of } \\
\text { HL (years) }\end{array}$ & $\begin{array}{c}\text { Degree of } \\
\text { deafness } \\
(\mathrm{dB} H L)^{\mathrm{a}}\end{array}$ & $\begin{array}{c}\text { Implant } \\
\text { type }\end{array}$ & $\begin{array}{l}\text { CI sound } \\
\text { processor }\end{array}$ & $\begin{array}{c}\text { CI sound } \\
\text { processing } \\
\text { strategy }\end{array}$ \\
\hline \multicolumn{11}{|l|}{ Music group (MG) } \\
\hline MG1 (F) & 49.8 & Cong. non spec. ${ }^{\mathrm{b}}$ & $\mathrm{R}$ & & 4 & 45.8 & $80-90$ & Nucleus $^{\mathrm{c}}$ & Freedom & ACE 900 \\
\hline MG2 (F) & 21.4 & Ototoxic & $\mathrm{R}$ & $\mathrm{X}$ & 0.7 & 20.7 & $>90$ & Nucleus & Freedom & ACE 250 \\
\hline MG3 (M) & 31.7 & Meningitis & $\mathrm{L}$ & $X$ & 5 & 30.2 & $80-90$ & Nucleus & Freedom & ACE 900 \\
\hline MG4 (M) & 56.0 & Cong. non spec. & $\mathrm{R}$ & $X$ & 8 & 48.0 & $80-90$ & Nucleus & Freedom & ACE 1800 \\
\hline MG5 (F) & 70.3 & Cong. non spec. & $\mathrm{R}$ & & 40 & 30.3 & $80-90$ & Nucleus & Freedom & ACE 900 \\
\hline MG6 (F) & 47.5 & Unknown & $\mathrm{L}$ & & 30 & 10.5 & $80-90$ & Nucleus & Freedom & ACE 1200 \\
\hline MG7 (F) & 56.2 & Hered. non spec. ${ }^{d}$ & $\mathrm{R}$ & $\mathrm{X}$ & 19 & 37.6 & $80-90$ & Nucleus & Freedom & ACE 1200 \\
\hline MG8 (M) & 58.5 & Meningitis & $\mathrm{R}$ & $X$ & 1.8 & 53.5 & $>90$ & Nucleus & Freedom & ACE 900 \\
\hline MG9 (F) & 29.1 & $\operatorname{Mon}^{\mathrm{e}}$ & $\mathrm{L}$ & & 10 & 19.1 & $80-90$ & Nucleus & Freedom & ACE 1200 \\
\hline Mean & 46.7 & & & & & 32.8 & & & & \\
\hline \multicolumn{11}{|l|}{ Control group (CG) } \\
\hline CG1 (F) & 44.8 & Unknown & $\mathrm{R}$ & $\mathrm{X}$ & 35 & 9.8 & $80-90$ & Nucleus & Freedom & ACE 1200 \\
\hline CG2 (M) & 60.4 & Unknown & $\mathrm{L}$ & $\mathrm{X}$ & 40 & 16.4 & $70-90$ & Nucleus & Freedom & ACE 900 \\
\hline CG3 (F) & 50.6 & Cong. non spec. & $\mathrm{R}$ & & 5 & 47.6 & $>90$ & A.B. ${ }^{f}$ & Harmony & Fid. 120 \\
\hline CG4 (M) & 63.5 & Cong. non spec. & $\mathrm{L}$ & $\mathrm{X}$ & 6 & 57.5 & $>90$ & Nucleus & Freedom & ACE 500 \\
\hline CG5 (F) & 63.0 & Unknown & $\mathrm{R}$ & $X$ & 58 & 5.0 & $70-90$ & Nucleus & Freedom & ACE 720 \\
\hline CG6 (F) & 45.8 & Hered. non spec. & $\mathrm{R}$ & $\mathrm{X}$ & 4 & 41.8 & $>90$ & Nucleus & Freedom & ACE 900 \\
\hline CG7 (M) & 72.5 & Unknown & $\mathrm{R}$ & & 41 & 21.5 & $70-90$ & Nucleus & Freedom & ACE 1200 \\
\hline CG8 (M) & 53.7 & Cong. non spec. & $\mathrm{L}$ & $\mathrm{X}$ & 5 & 48.7 & $70-90$ & Nucleus & Freedom & ACE 500 \\
\hline CG9 (M) & 73.3 & Trauma & $\mathrm{R}$ & & 54 & 19.3 & $70-90$ & Nucleus & СР 810 & ACE 720 \\
\hline Mean & 58.6 & & & & & 29.7 & & & & \\
\hline
\end{tabular}

${ }^{a}$ Measured as the average of pure-tone hearing thresholds at 500, 1,000, and 2,000 Hz, expressed in DB with reference to normal thresholds. Ranges indicate a difference between left and right ear hearing thresholds. ${ }^{\mathrm{b}}$ Nonspecified congenital HL. $\quad{ }^{\mathrm{c}}$ Cochlear. $\quad{ }^{\mathrm{d}}$ Nonspecified hereditary HL. ${ }^{\mathrm{e}}$ Mondini dysplasia. ${ }^{\mathrm{f}}$ Advanced Bionics.

their estimated age at onset of deafness $(0.7-6$ years) and main use of signed language as communicative strategy. The remaining 13 participants had a postlingual or progressive onset of HL (6-58 years), as indicated by their main use of residual hearing, supported by lipreading. In accordance with local practice, all CI participants followed standard aural/oral therapy for 6 months in parallel with the music-training study. The therapy program includes weekly $1-\mathrm{hr}$ individually adapted sessions, and trains speech perception and articulation. Table 1 lists the demographic and clinical data for the 18 participants.

NH reference. To obtain an $\mathrm{NH}$ performance reference, we recruited a group of $\mathrm{NH}$ adults (four women, two men, $M_{\text {age }}=$ 54.29 years, age range: $47-64$ years) for a one-time test session. All NH participants met the criteria for $\mathrm{NH}$ by passing a full audiometric test.

\section{Musical Background}

To account for past training and experience, all participants filled out a questionnaire concerning their musical background. The questionnaire was adapted from Gfeller et al. (2000) and contained questions about the level of formal music training and activities. The responses showed that no participants had a professional musical background, or any formal music instruction beyond secondary school.

\section{Design}

Within 14 days after switch-on of the implant, the participants in the two CI groups completed speech and music perception tests (baseline). Subsequently, the participants received either musical ear training (music group) or no musical ear training (control group) for 6 months. Test procedures were repeated after 3 months (midpoint) and after 6 months (end point). The NH participants completed the entire music and speech test battery once at a single test session.

\section{Musical Test Battery}

To assess the development of the participants' musical discrimination skills, we created a battery consisting of five music tests: (1) musical instrument identification (MII), (2) melodic contour identification (MCI), (3) pitch ranking (PR), (4) rhythmic discrimination (RD), and (5) melodic discrimination (MD).

(1) The MII test required the participant to identify the instrument playing randomly presented parts $(\mathrm{A}, \mathrm{B}, \mathrm{C}$, or $\mathrm{D})$ of a well-known Danish children's song (Mariehønen Evigglad/Ladybug Ever Happy, Figure 1). Instruments were presented in random order. The MII test was divided into two subtests: MII.1 and MII.2. Before testing, each participant confirmed that they were familiar with each of the instruments.

MII.1 was a 3-alternative forced-choice test including three instruments from different instrument families: flute (woodwind), piano (pitched percussion), and double bass (plucked string). Before MII.1, the participant was presented with each instrument twice, playing melody part A (see Figure 1), while corresponding icons were shown on the computer screen. Participants for whom this task was particularly challenging or time-consuming would not proceed to the more advanced MII.2.

MII.2 was an eight-alternative forced-choice test including the instruments from MII.1, along with clarinet (woodwind), violin (string), trumpet (brass), trombone (brass), and guitar (plucked 
A $.=\mathbf{1 1 0} . \Omega=\Omega \cdot \quad$ Ladybug Ever Happy

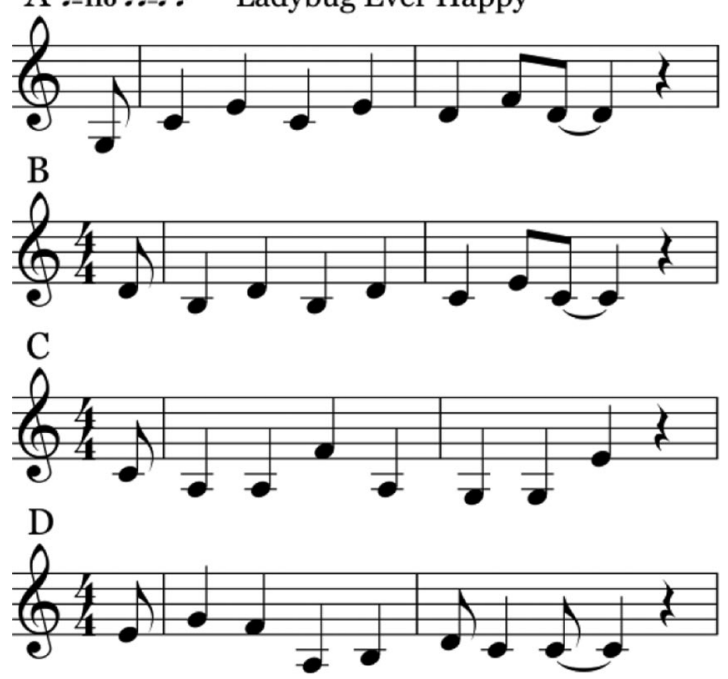

Figure 1. "Ladybug Ever Happy" in musical notation. The melody comprises an octave from G3 $(196 \mathrm{~Hz})$ to G4 $(392 \mathrm{~Hz})$. Letters A to D indicate the four parts presented randomly in the test.

string). Before this test, the five new instruments were presented twice, playing melody part A.

The division of the melody into four parts was inspired by the Zurich Music Test Battery (Büchler, 2008). The random presentation of phrases ensures that instrument identification is not associated with a single melodic feature.

(2) The MCI test required the participant to judge whether the melodic contour of a 5-note sequence was either (1) rising, (2) falling, (3) flat, (4) rising-falling, or (5) falling-rising (see Figure 2). The sequences were played with the timbre of a modified digital sampling of a clarinet (3-tone complex) diatonically in the key of A major, ranging from A3 $(220 \mathrm{~Hz})$ to E4 $(329.6 \mathrm{~Hz})$. Contours were presented in random order, with each variant appearing twice, for a total of 10 trials. The MCI test is an existing part of the Zurich Music Test Battery (Büchler, 2008), originally adapted from Galvin et al. (2007).

(3) The PR test consisted of 28 trials requiring the participant to determine the higher of two piano tones. A range of 28 semitones (STs; 2.3 octaves) was used in the fundamental frequency range from E3 $(164.8 \mathrm{~Hz})$ to $\mathrm{G \# 5}(830.6 \mathrm{~Hz})$. The trials were divided equally into ascending and descending trials. Direction of the interval was randomized across trials. Note distance was divided into three categories: small ( $1-3 \mathrm{STs}, n=9)$, medium (4-7 STs, $n=10)$, and large $(>7$ STs, $n=9)$. The tones had a rhythmic value of a half note and were played back at 85 beats per minute (BPM), equaling a tone duration of $1,400 \mathrm{~ms}$. The design of the test is similar to Test 1 used by Looi, McDermott, H., McKay, C., and Hickson (2004).

(4) The RD test presented 28 pairs of rhythmic 1-bar phrases and required the participant to judge whether the two phrases were the same or different (see Figure 3). Half of the trials were identical (same), and half contained a violation of the rhythm (different). Five patterns were violated by a delayed beat, four by an anticipated beat, and five by addition or omission of a beat. Beats were delayed or anticipated by eighth or sixteenth notes, which equals 300 and $150 \mathrm{~ms}$, respectively. The RD phrases were in 4/4 time, played at 100 BPM, and used the sampled sound of a cowbell for the first part (call) and the sound of a woodblock for the second (response). A 4-beat metronome count-in preceded all RD trials. Preceding the test, participants were carefully prepared for the three different sounds of the count-in, the "call," and the "response," and informed that their task was to compare the second and the third pattern.

(5) The MD test presented 28 pairs of melodic 1-bar phrases and required the participant to judge whether the pairs were the same or different (see Figure 3). Half of the pairs were identical (same), and half had identical rhythm patterns but contained a violation of pitch (different). In five of these, the violation also constituted a violation of contour. In nine trials, the deviant note was diatonic (within the scale), and in five trials, the deviant note was nondiatonic (outside the scale). The deviant note was either 1 to 2 STs $(N=9), 3-7$ STs $(N=4)$, or $>7$ STs $(N=3)$ away from the standard. The MD phrases were played by pure tones in the pitch range from G3 $(196 \mathrm{~Hz})$ to $\mathrm{D \# 5}(622.3 \mathrm{~Hz})$, were in $4 / 4$ time, and played back at a tempo of 100 BPM. Of the 28 melodies, 13 were in the major key, 11 in the minor key, and 4 were neither (i.e., contained no determining major nor minor third). Preceding the MD test, participants were informed that the rhythmic content of the two phrases was identical in all pairs and that their task was to detect possible changes in the melodic content.

To ensure variation and to account for ceiling effects, the RD and the MD tests both covered a wide range of musical styles and complexity (see Figure 3). The design of the MD and RD tests was adapted from the Musical Ear Test (Hansen, Wallentin, \& Vuust, 2012; Wallentin, Nielsen, Friis-Olivarius, Vuust, \& Vuust, 2010).

\section{Test Procedure}

At all occasions of the MCI, PR, MD, and RD tests, the participants were given two example trials with feedback before the actual test, while looking at the corresponding response buttons on the computer screen. No feedback was given during any of the music tests.

All tests in the music battery were presented in the computerized test environment MACarena (Lai, 2000), played back on a laptop computer through an active loudspeaker (Fostex 6301B, Fostex

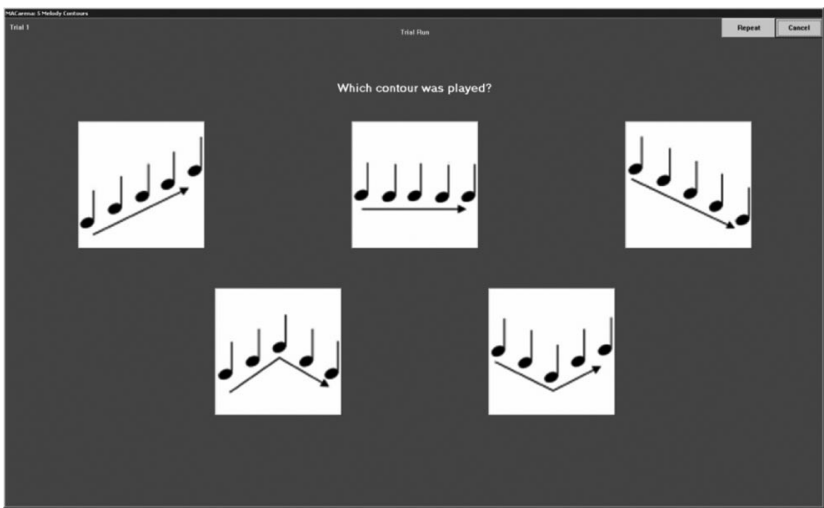

Figure 2. The melodic contour identification test computer screen with pictorial representations of the five contours 


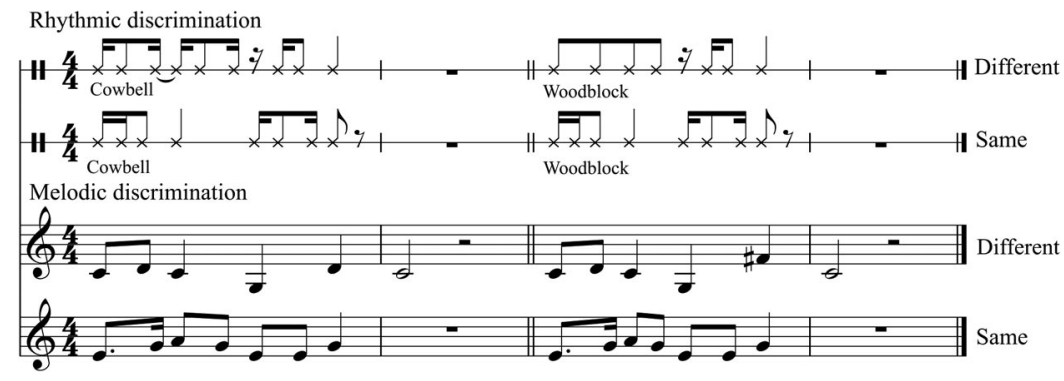

Figure 3. Example trials from the rhythmic and melodic discrimination tests. For each pair of rhythms or melodies, the participant makes a same/different judgment.

Company, Japan) placed in front of the participant. The stimuli were presented at $65 \mathrm{~dB}$ sound pressure level (SPL), and CI users were instructed to adjust their processors to a comfortable loudness level. Participants used their preferred processor settings during the entire test session. The stimuli were presented in random order, and the test examiner registered the participants' responses by clicking corresponding pictorial representations on the computer screen. One person administered all musical tests.

\section{Speech Tests}

We assessed the participants' speech perception progress by two different tests: (1) the Hagerman speech perception test (HAG) and (2) an emotional prosody recognition test (EPR).

HAG is an open-set test, which presents sentences organized in lists of 10 in background noise. The sentences have identical name-verb-number-adjective-noun structures such as "Peter buys five red flowers," which the participant is required to repeat. Each sentence is scored 1 to 5 , with each part of the sentence scored separately. The participants were given one example list with feedback and two trial lists without feedback (maximum score $=$ 100 points). To reduce the risk of learning effects, we used different lists at the three times of testing. Sound was played back at the most comfortable hearing level using the same equipment and procedure as in the music tests.

The EPR test required the participant to judge from the prosodic content of 44 different spoken words and sentences, whether they expressed a sad or happy emotion. The EPR trials were taken from the Danish Emotional Speech Database (Engberg \& Hansen, 1996), which holds words and sentences in Danish, spoken by two female (age: 32 and 52 years, respectively) and two male (age: 32 and 52 years, respectively) actors in five different emotions. The 44 EPR trials were compiled from 88 happy and sad samples and balanced on emotion (22 happy, $22 \mathrm{sad}$ ) and speaker gender and age. Single words were "yes" and "no," while sentences were everyday utterances. The trials were presented in random order. The procedure of the EPR test was similar to that of the music tests (see Test procedure).

\section{The Musical Ear-Training Program}

Participants who were assigned to the music group committed themselves to weekly 1-hr music-training solo sessions and home practice for a period of 6 months. The music-training sessions were led by a professional music teacher and took place in a well- isolated rehearsal room at the Royal Academy of Music in Aarhus, Denmark. Home practice was based on applications that were installed on the participants' personal computers. The intention of the program was to train perception and discrimination of (1) pitch, (2) rhythm, and (3) timbre through singing, playing, and listening exercises.

Pitch-related training aimed at developing a sense of basic musical attributes such as high/low, up/down, far/close, and melodic direction. This was facilitated by the following:

- Singing: The participants were required to vocalize and imitate short phrases with a range of vowels and to sing well-known Danish songs of their own choice. Emphasis was put on rhythmic precision, articulation of the lyrics, and intonation.

- Playing: The participants were required to imitate short phrases and to play well-known folk and children's songs with a limited range of notes (c4 [261.6 Hz] to g4 [392 Hz]) on the piano.

- Listening: Two audiovisual computer applications trained the participant in identifying and distinguishing either (a) seven simple well-known monophonic melodies played on piano in the key of $\mathrm{C}$ major at a tempo of 90 BPM or (b) Five-note sequences with different melodic contours played with a 3-tone complex sound and presented with four different pitch distances (4 STs, 3 STs, diatonically, and $1 \mathrm{ST})$ in the frequency range from A3 $(220 \mathrm{~Hz})$ to F\#6 (1,480 Hz). Application $a$ consisted of two sections. In the first section, the participant had the opportunity to get acquainted with the melodies by clicking graphic representations in standard music notation. In the second section, the participant was required to match presented melodies with corresponding titles on the screen.

Application $b$ was divided in three sections. In section one and two, the participant had the opportunity to get acquainted with rising, falling, and flat contours and rising - falling and fallingrising contours, respectively. In the third section, the participant was required to match presented contours with corresponding icons on the screen. The stimuli from the MCI test were part of the training trials, but the five different contours appeared either in groups of three (rising, falling, flat) or two (rising-falling, falling_rising)—not simultaneously.

In both applications, the participant had the opportunity to listen to the different choices by clicking corresponding pictorial representations on the screen before answering. The correct answer to each question was displayed when the participant pressed the right arrow key. 
Rhythm-related training aimed at strengthening perception of basic features of rhythm such as pulse/meter, beat/subdivision, fast/slow, and weak/strong. This was facilitated by the following:

- Drumming: The participants were required to replicate rhythm patterns by clapping, tapping, or drumming, with focus on accentuation of beats and dynamic expression.

- Energizing: The participants practiced the rhythm of specific melodies by articulating lyrics and rhythm only.

- Listening: Two computer applications required the participants to either (a) match the sound of a rhythm pattern with a rhythm pattern in musical notation or (b) imitate series of patterns with increasing difficulty by tapping. There was no similarity between the rhythm-training applications and the RD test.

Timbre-related training aimed at improving the distinction between light/dark, attack/decay, and hard/soft in the quality of the tone of different instruments. This was facilitated using a computer application, which trained the participants in matching the sound of different musical instruments with pictorial representations. The instruments appeared in two sections according to family: (1) woodwind (flute and clarinet) and brass (trumpet and trombone), and (2) strings (violin and cello) and plucked strings (guitar and double bass). As an extra instrument, an accordion was included in the string section. The instruments were presented by two short melodies composed for the purpose.

For home training, all computer applications were installed on the participants' personal computers. Participants were guided in managing the applications and instructed to train regularly-approximately $30 \mathrm{~min} / \mathrm{d}$.

Software used. Training applications were programmed as slideshows in MS Powerpoint (Microsoft Corp., USA). PR tone pairs and MII, MD, and RD phrases were programmed with MIDI in Cubase 4.1 (Steinberg Media Technologies GmbH, Hamburg, Germany). MD pure tones were produced and normalized in Audacity (http://audacity.sourceforge.net), and played back by the software sampler Halion 2.0 (Steinberg). The PR piano sound and the musical instrument sounds used in the MII tests and the timbre-training application were high-quality samplings taken from the library found in Halion 1 (Steinberg).

Hearing aids. Participants who supplemented their CI with a contralateral HA were allowed to keep it switched on during training. However, to maintain comparable test conditions, they were instructed to turn it off and keep it plugged in during testing.

Statistical methods. All music and speech test scores were calculated as the percentage of correctly answered items (0\%$100 \%$ ). Data were plotted and analyzed using Sigmaplot for Windows 11.0 (Systat Software Inc) and NCSS 8 (Hintze, 2012). To identify main effects of group and time and possible interactions between these effects, we performed separate mixed-effects analyses of variance (ANOVAs) for each of the tests, with a betweensubject factor of group (music or control group) and a withinsubject factor of time $(0,3$, and 6 months). In cases where effects were significant, we proceeded with Tukey-Kramer multiplecomparison tests for pairwise differences between means. Furthermore, we compared the end-point performance test scores of the music group and the control group with the $\mathrm{NH}$ reference using two-sample $t$ tests. In cases of test scores with nonnormal distribution, the analyses were performed using the nonparametric Wilcoxon's/Mann-Whitney $U$ test. In the following sections, midpoint gain refers to the change in mean scores from baseline to midpoint and end-point gain refers to the change in mean scores from baseline to end point. Mid- and end-point scores refer to absolute mean values at the two milestones.

To calculate an overall music score for each participant, which took the different chance levels of the music tests into account, we standardized, summed, and averaged the raw performance scores from the six music tests at each point of testing. In the following sections, the group mean of these scores is referred to as overall music z-scores. By subtracting overall baseline music $z$-scores from overall midpoint and overall end-point music $z$-scores, we calculated 3- and 6-month gain $z$-scores. In the following sections, these scores are referred to as overall music midpoint and endpoint gain z-scores, respectively. To look for possible significant relationships, we carried out Pearson correlation analyses with performance scores, $z$-scores, and background variables across all participants as well as within and between groups.

To test whether the two CI groups had comparable prerequisites for the study, we compared the baseline scores of each group for all tests. Normally distributed data were analyzed using one-way ANOVAs, whereas data with non-normal distributions were analyzed using the Kruskal-Wallis one-way ANOVA on ranks. The results of the analysis showed no significant difference in the mean baseline scores of the two groups on any test (MII.1: KruskalWallis, $\mathrm{H}(1)=0.13, p=.72$; MII.2: $F(1 / 13)=0.05, p=.826$; MCI: Kruskal-Wallis, H(1) $=1.68, p=.19$; PR: $F(1 / 17)=0.39$, $p=.542 ; \mathrm{RD}: F(1 / 17)=0.05, p=.82 ; \mathrm{MD}: F(1 / 16)=0.61, p=$ .45 ; HAG: $F(1 / 15)=0.00, p=.991$; EPR: Kruskal-Wallis, $\mathrm{H}$ (1) $=0.29, p=.59)$.

\section{Results}

\section{Musical Skills}

The overall end-point music gain $z$-scores of the music group were significantly higher than those of the control group $(t(16)=$ $4.167, p=.0007)$. There was no significant difference between the midpoint music gain $z$-scores of the music group and the control group $(t(16)=1.716, p=.105$; see Figure 4$)$.

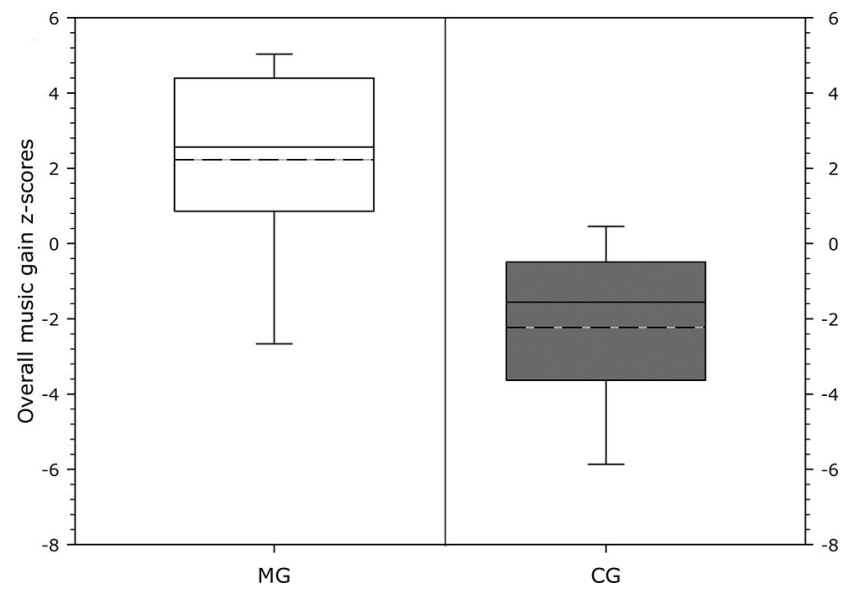

Figure 4. Box plot of overall end-point music gain $z$-scores for the music group (MG) and the control group (CG). Error bars show 10th/90th percentile. Solid box lines: median. Dotted box lines: mean. 
Musical instrument identification. The main effect of time on the MII.1 was significant $(F(2,53)=6.0, p=.006)$, driven by a 10.65 percentage points (pp) midpoint gain $(p=.034)$ and a $11.58 \mathrm{pp}$ end-point gain $(p=.004)$ across groups. There was no effect of group and no interaction between group and time (Table 2 and Figure 5). The MII.1 end-point scores of the music group were not significantly different from the NH scores (MannWhitney $U=21.0, p=.272$ ), whereas the end-point scores of the control group were significantly lower than the NH (MannWhitney $U=12.0, p=.042$; see Figure 6).

The main effect of time on the MII.2 was significant $(F(2,44)=$ $9.65, p=.0007)$, driven by a 15.95 pp end-point gain $(p=.003)$ across groups. We found no main effect of group. There was a significant interaction between group and time $(F(2,44)=6.99$, $p=.004)$, suggesting that the groups had a different progress over time. According to post hoc comparisons, this was driven by a significant $23.65 \mathrm{pp}$ difference between the music group and the control group end-point scores $(p=.029)$ and an absence of

Table 2

Main Effects of Group and Time and Interactions in the Mixed-Effects ANOVAs of the Eight Music and Speech Tests

\begin{tabular}{|c|c|c|}
\hline Tests & $F(d f)$ & $p$ \\
\hline \multicolumn{3}{|l|}{ MII.1 } \\
\hline Group & $0.93(1,53)$ & .349 \\
\hline Time & $6.00(2,53)$ & $.006^{*}$ \\
\hline Group/time & $2.25(2,53)$ & .121 \\
\hline \multicolumn{3}{|l|}{ MII.2 } \\
\hline Group & $2.16(1,44)$ & .1687 \\
\hline Time & $9.65(2,44)$ & $.0007^{*}$ \\
\hline Group/time & $6.99(2,44)$ & $.004^{*}$ \\
\hline \multicolumn{3}{|l|}{ MCI } \\
\hline Group & $21.60(1,53)$ & $.0002 *$ \\
\hline Time & $5.94(2,53)$ & $.006^{*}$ \\
\hline Group/time & $4.92(2,53)$ & $.0146^{*}$ \\
\hline \multicolumn{3}{|l|}{ PR } \\
\hline Group & $1.30(1,53)$ & .270 \\
\hline Time & $2.16(2,53)$ & .132 \\
\hline Group/time & $1.35(2,53)$ & .275 \\
\hline \multicolumn{3}{|l|}{ RD } \\
\hline Group & $0.61(1,53)$ & .447 \\
\hline Time & $2.53(2,53)$ & .096 \\
\hline Group/time & $3.97(2,53)$ & $.029^{*}$ \\
\hline \multicolumn{3}{|l|}{ MD } \\
\hline Group & $0.66(1,50)$ & .429 \\
\hline Time & $2.29(2,50)$ & .119 \\
\hline Group/time & $0.14(2,50)$ & .869 \\
\hline \multicolumn{3}{|l|}{ HAG } \\
\hline Group & $0.05(1,47)$ & .832 \\
\hline Time & $21.86(2,47)$ & $.0001^{*}$ \\
\hline Group/time & $0.10(2,47)$ & .908 \\
\hline \multicolumn{3}{|l|}{ EPR } \\
\hline Group & $0.26(1,53)$ & .615 \\
\hline Time & $4.27(2,53)$ & $.023^{*}$ \\
\hline Group/time & $3.17(2,53)$ & .055 \\
\hline
\end{tabular}

Note. Main effects and interaction of the mixed-effects ANOVA with group (music group and control group) as the between-subject variable, and time (baseline, midpoint, and end point) as the within-subject variable. MII.1 = musical instrument identification 1; MII.2 = musical instrument identification test $2 ; \mathrm{MCI}=$ melodic contour identification; $\mathrm{PR}=$ pitch ranking; $\mathrm{RD}=$ rhythmic discrimination; $\mathrm{MD}=$ melodic discrimination; HAG $=$ Hagerman sentence test; EPR = emotional prosody recognition. ${ }^{*}$ Term significant at alpha $=.05$. difference in the initial scores (Table 2 and Figure 5). The MII.2 end-point scores of the music group were not significantly different from the NH scores (Mann-Whitney $U=8.5, p=.073$ ), whereas the MII.2 end-point scores of the control group were significantly lower than the NH scores (Mann-Whitney $U=0.0$, $p=.001$; see Figure 6).

Ceiling performance was observed in the end-point scores of seven music group, four control group, and all $\mathrm{NH}$ participants in the MII.1 subtest. One participant in the music group and two participants in the control group did not perform the more challenging MII.2 subtest.

Melodic contour identification. For the MCI test, there was a significant effect of group $(F(1,53)=21.60, p=.0002)$, a significant effect of time $(F(2,53)=5.94, p=.006)$, and a significant interaction between group and time $(F(2,53)=4.92$, $p=.0146)$. Post hoc tests confirmed that both main effects and interaction were driven by a significant $29.24 \mathrm{pp}$ difference between the music group and the control group midpoint scores $(p<$ $.001)$ and a significant $34.11 \mathrm{pp}$ difference between the music group and the control group end-point scores $(p<.001)$, with the absence of significant difference in the initial scores (Table 2 and Figure 5). Both groups scored significantly below the NH level at the end-point measurement (music group: Mann-Whitney $U=$ 10.0, $p=.046$; control group: Mann-Whitney $U=0.0, p<$ $.001)$. Ceiling performance was observed in one of nine music group participants and four of six NH participants (see Figure 6).

Pitch ranking. Despite a trend toward a higher end-point gain $(+12.4 \mathrm{pp})$ in the music group relative to the control group $(+3.18$ $\mathrm{pp}$ ), the mixed-effects ANOVA of the PR test scores showed no significant main effects and no interaction (Table 2 and Figure 5). Both groups scored significantly below the $\mathrm{NH}$ level at the endpoint measurement (music group: $t(13)=-3.31, p<.006$; control group: $t(13)=-3.22, p=.007$; see Figure 6).

Rhythm discrimination. Analysis of RD test results showed no main effects of group or time. A significant interaction, however, was found between group and time $(F(2,53)=3.97, p=$ .029), indicating that the groups developed differently over time. The interaction was driven by a significant $10.73 \mathrm{pp}$ difference between the music group and the control group end-point scores $(p=.015)$ and an absence of difference in the initial scores (Table 2 and Figure 5). The RD end-point scores of the music group were nonsignificantly higher than the $\mathrm{NH}$ scores $(t(13)=0.289, p=$ .777), whereas the end-point scores of the control group were significantly lower than the NH scores $(t(13)=-1.96, p=.07$; see Figure 6).

Melodic discrimination. The analysis of the MD test scores showed neither significant main effects nor a significant interaction (Table 2 and Figure 5). Both groups scored significantly below the NH level (music group: $t(13)=-2.948, p=.011$; control group: $t(13)=-3.129, p=.009$; see Figure 6). Owing to test fatigue, one participant in the music group did not perform the MD (see Figure 6).

Appendix A plots individual baseline, midpoint, end-point, and mean scores for all six music tests, for both CI groups.

\section{Speech Performance}

Speech perception. The analysis of the HAG results showed a significant effect of time $(F(2,47)=21.86, p<.001)$. Post hoc 


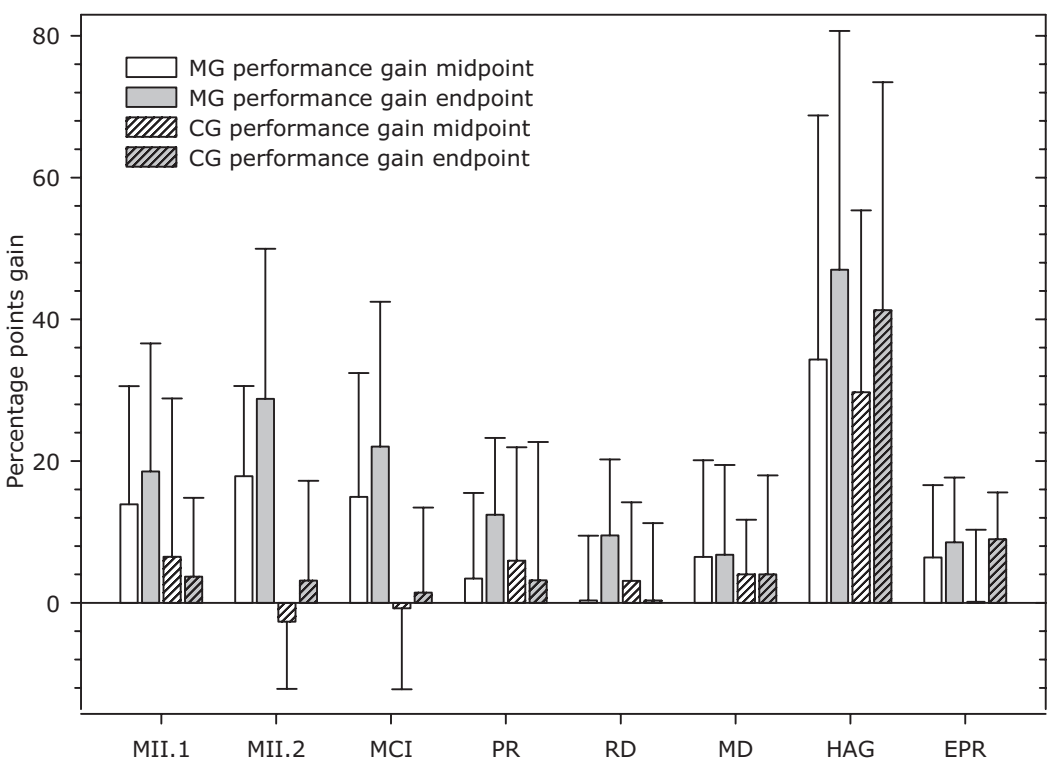

Figure 5. Bar graph showing gains of the music group (MG) and the control group (CG) from baseline to midpoint and baseline to end point, in the six music and two speech tests. Error bars $=$ SD. MII.1 = musical instrument identification 1; MII.2 = musical instrument identification test 2 ; MCI $=$ melodic contour identification; $\mathrm{PR}=$ pitch ranking; $\mathrm{RD}=$ rhythmic discrimination; $\mathrm{MD}=$ melodic discrimination; $\mathrm{HAG}=$ Hagerman sentence test; $\mathrm{EPR}=$ emotional prosody recognition.

tests showed that the effect was driven by a 32.02 pp midpoint gain $(p<.001)$ and a 44.14 pp end-point gain $(p<.001)$ across groups. There was no effect of group and no interaction between group and time (Table 2 and Figure 5). Both groups scored significantly below the $\mathrm{NH}$ level at the six-month measurement (music group: Mann-Whitney $U=3.0, p=.003$; control group: MannWhitney $U=0.0, p=.001$; see Figure 6). Ceiling performance was observed in one music group participant and in all $\mathrm{NH}$ participants. Four music group participants and two control group participants scored within the 90th percentile at end point. There was considerable variability in performance in both groups (music group range: 93 [7-100], control group range: 95 [3-98]; see Figure 5). To maintain a true comparison between the groups, two control group participants were excluded from the HAG data analysis owing to a floor effect at all three points of testing.

Emotional prosody recognition. The analysis of EPR scores showed a main effect of time $(F(2,53)=4.27, p=$ $.023)$, but no main effect of group and no interaction between group and time. The time effect was driven by a $6.31 \mathrm{pp}$ end-point gain ( $p=.004)$ across groups. The main progress of the music group took place from baseline to midpoint $(+5.7$ $\mathrm{pp})$, whereas the main progress of the control group took place from midpoint to end point $(+8.8 \mathrm{pp})$, indicating a trend toward a faster development in the music group. Both groups scored well above chance levels, but significantly below the $\mathrm{NH}$ level (music group: $t(13)=-4.236, p<.001$; control group: $t(13)=-2.860, p=.013$; see Figure 6). Ceiling performance was observed in one $\mathrm{NH}$ participant.

Table 2 shows $F$-ratios, degrees of freedom, and $p$ values for main effects and interaction for each of the eight tests. Table 3 shows mean scores and standard deviations of all tests at each milestone. Appendix B plots individual baseline, midpoint, end-point, and mean scores for the two speech tests, for both CI groups.

\section{Correlations}

Relationship between music and speech perception. We found significant relationships between overall music $z$-scores and HAG scores at all three points of measurement, across all participants regardless of group. Furthermore, we found a significant relationship between overall music $z$-scores and EPR scores of the music group at mid- and end point. Finally, the EPR and HAG scores of the music group correlated significantly at mid- and end point (see Table 4). Other correlations between overall music $z$-scores and HAG and EPR across participants and within groups vary in strength. We found no significant relationship between overall music gain $z$-scores and HAG gain scores or EPR gain scores, either across all participants or within groups at any point of time (see Table 4).

Background variables versus music and speech perception/gain. Use of contralateral HA showed no significant relationship with any single speech or music performance. However, across all participants, use of contralateral HA showed a borderline significant negative correlation with overall music endpoint gain $z$-scores $(r=-.451, p=.06)$, and a significant negative correlation with EPR end-point gain scores $(r=-.560$, $p=.01)$. Age showed a significant negative correlation with overall music gain $z$-scores at midpoint $(r=-.650, p=.003)$, as well as end point $(r=-.543, p=.02)$, across all participants. Duration of deafness correlated negatively with midpoint HAG scores $(r=-.668, p=.004)$ and end-point HAG scores $(r=$ $-.512, p=.04)$ across all participants. 


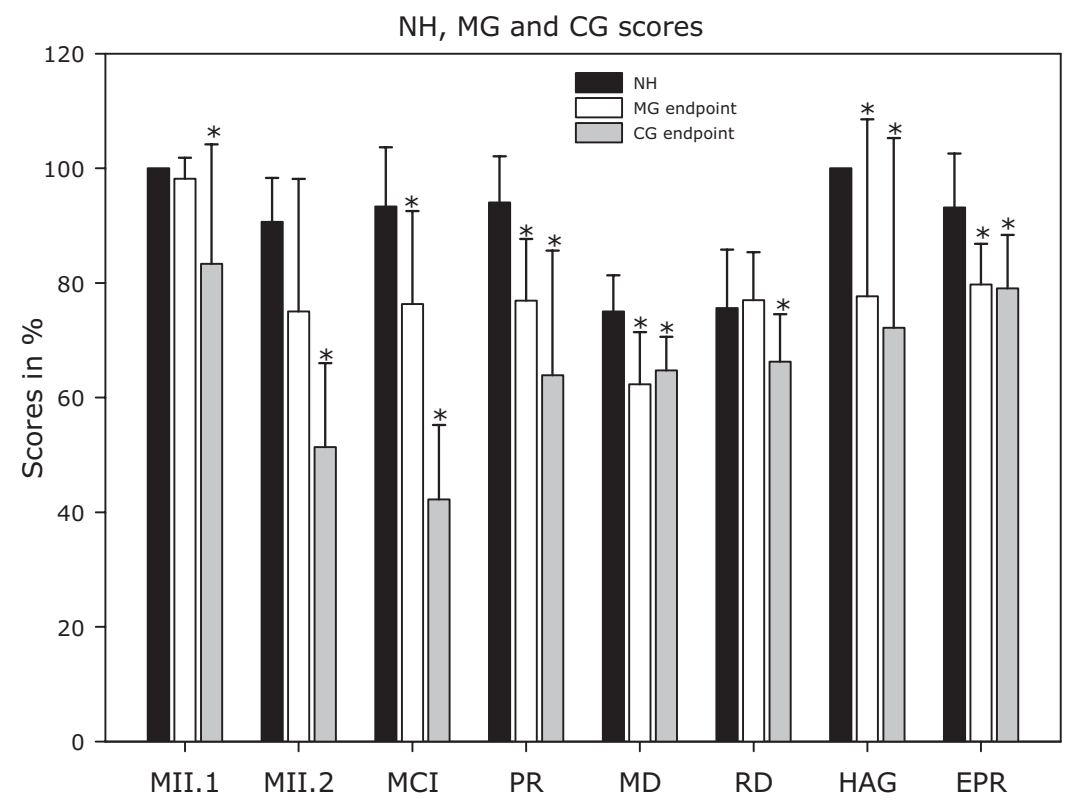

Figure 6. Bar chart showing normal hearing (NH), music group (MG), and control group (CG) end-point scores in the six music and two speech tests. Error bars $=\mathrm{SD} .{ }^{*}=$ the score is significantly lower than the NH performance level. MII.1 = musical instrument identification 1; MII.2 = musical instrument identification test $2 ; \mathrm{MCI}=$ melodic contour identification; $\mathrm{PR}=$ pitch ranking; $\mathrm{RD}=$ rhythmic discrimination; $\mathrm{MD}=$ melodic discrimination; $\mathrm{HAG}=$ Hagerman sentence test; EPR = emotional prosody recognition.

\section{Discussion}

This study shows that 6 months of musical ear training significantly improved the overall music perception of the participants in the music group, compared with the control group. In particular, with regard to timbre, melodic contour, and rhythm, we saw a significant effect of the training, while PR showed a trend toward improved performance. Furthermore, the music group produced posttraining scores in discrimination of timbre and rhythm that were comparable with those of the NH group. In contrast, the control group showed no significant progress within these areas, and performed significantly poorer than the $\mathrm{NH}$ group in discrimination of timbre and rhythm. Both groups had modest progress in discrimination of melody and scored significantly below the NH level. Despite a significant consistent relationship between overall music performance and speech perception, we found no significant effect of music training on speech perception. Overall music performance correlated significantly with recognition of emotional prosody exclusively in the music group, and the music group's EPR skills showed a trend toward faster progress relative to the control group. The findings suggest that musical training may be beneficial for music discrimination skills, but not necessarily for speech perception skills of CI users.

Music training has been implemented with positive results in previous studies involving CI listeners (Galvin et al., 2007; Gfeller et al., 2000, 2002b). These studies were primarily based on computer-mediated training of isolated musical tasks such as pitch, timbre, or melody recognition, whereas the present study used longitudinal one-to-one training within three different musical domains. Furthermore, in contrast to previous studies, the participants in the current study were "naïve" CI users, that is, without implant experience. Finally, it is important to point out that the program aimed to improve perception of music as a result of a mix of music making and listening, that is, there was no direct training for the tests. Thus, our results suggest that this music-training approach has the ability to significantly affect the general music discrimination skills, even in CI listeners with no previous implant experience.

\section{Musical Instrument Identification}

The largest impact of the musical training was found on the music group participants' ability to identify musical instruments. This finding is in line with other studies that showed enhanced abilities to discriminate timbre after short- and long-term computer-assisted training (Leal et al., 2003; Pressnitzer, Bestel, \& Fraysse, 2005; Fujita \& Ito, 1999). Furthermore, the music group achieved an average end-point level in the advanced subtest of the MII that was comparable with the NH level. This indicates that the implant transmits sufficient spectral information to allow CI users to learn to identify musical instruments by their timbre, and is particularly encouraging, as most studies that examined discrimination of timbre in CI users have found performance significantly poorer than that of NH participants (Gfeller et al., 2002; McDermott \& Looi, 2004). The result is important, as improved perception of timbre may add positively to the aesthetic enjoyment associated with music listening. Furthermore, CI listeners' ability to distinguish several instruments, playing at the same time, could be positively affected. Finally, improved discrimination of timbre may be beneficial in aspects of listening such as recognition of gender or speaker in auditory-only acoustic communication, which 
Table 3

Mean Scores of Music and Speech Tests

\begin{tabular}{|c|c|c|c|c|c|c|}
\hline \multirow[b]{2}{*}{ Tests } & \multicolumn{2}{|c|}{ Music group } & \multicolumn{2}{|c|}{ Control group } & \multicolumn{2}{|c|}{ Normal hearing group } \\
\hline & $M$ & $S D$ & $M$ & $S D$ & $M$ & $S D$ \\
\hline \multicolumn{7}{|l|}{ MII.1 } \\
\hline Baseline & 78.7 & 19.14 & 79.63 & 22.86 & - & - \\
\hline Midpoint & 93.52 & 11.61 & 86.12 & 22.03 & - & - \\
\hline End point & 98.15 & 3.65 & 83.33 & 20.83 & 100 & 0 \\
\hline \multicolumn{7}{|l|}{ MII.2 } \\
\hline Baseline & 46.22 & 19.83 & 48.23 & 10.02 & - & - \\
\hline Midpoint & 64.08 & 23.80 & 45.55 & 14.32 & - & - \\
\hline Group/time & 75.01 & 21.39 & 51.36 & 14.63 & 90.66 & 7.64 \\
\hline \multicolumn{7}{|l|}{ MCI } \\
\hline Baseline & 54.28 & 18.19 & 40.77 & 8.96 & - & - \\
\hline Midpoint & 69.24 & 16.60 & 40 & 11.18 & - & 一 \\
\hline End point & 76.33 & 16.20 & 42.22 & 13.01 & 93.16 & 9.41 \\
\hline \multicolumn{7}{|l|}{ PR } \\
\hline Baseline & 64.46 & 12.82 & 60.71 & 12.74 & - & - \\
\hline Midpoint & 67.9 & 16.23 & 66.66 & 8.95 & - & - \\
\hline End point & 76.9 & 10.77 & 63.88 & 21.76 & 94.03 & 8.05 \\
\hline \multicolumn{7}{|l|}{ RD } \\
\hline Baseline & 67.46 & 16.70 & 65.92 & 11.17 & - & - \\
\hline Midpoint & 67.81 & 11.87 & 69.04 & 9.81 & - & - \\
\hline End point & 76.98 & 8.39 & 66.25 & 8.27 & 75.6 & 10.20 \\
\hline \multicolumn{7}{|l|}{ MD } \\
\hline Baseline & 55.5 & 14.92 & 60.71 & 12.22 & - & - \\
\hline Midpoint & 61.98 & 9.91 & 64.71 & 12.13 & - & - \\
\hline End point & 62.29 & 9.14 & 64.72 & 5.87 & 75 & 6.35 \\
\hline \multicolumn{7}{|l|}{ HAG } \\
\hline Baseline & 30.66 & 38.55 & 30.85 & 33.81 & - & - \\
\hline Midpoint & 65 & 30.19 & 60.57 & 35.90 & - & - \\
\hline End point & 77.66 & 30.86 & 72.14 & 33.15 & 100 & 0 \\
\hline \multicolumn{7}{|l|}{ EPR } \\
\hline Baseline & 71.85 & 9.84 & 70.05 & 7.81 & - & - \\
\hline Midpoint & 77.56 & 8.09 & 70.21 & 13.07 & - & - \\
\hline End point & 75.5 & 6.80 & 79.03 & 9.35 & 93.33 & 10.32 \\
\hline
\end{tabular}

Note. Mean performance scores for the six music and two speech tests of the three groups at the three points of testing. MII.1 = musical instrument identification $1 ;$ MII.2 = musical instrument identification test 2 ; $\mathrm{MCI}=$ melodic contour identification; $\mathrm{PR}=$ pitch ranking; $\mathrm{RD}=$ rhythmic discrimination; $\mathrm{MD}=$ melodic discrimination; $\mathrm{HAG}=$ Hagerman sentence test; $\mathrm{EPR}=$ emotional prosody recognition.

are notoriously challenging with CIs (Vongphoe \& Zeng, 2005). The simple subtest of the MII seems to have been too easy, signified by the ceiling effects, which may explain the absence of significant indications of a training effect.

\section{Melodic Contour Identification}

The participants in the music group significantly improved in their ability to identify a melodic contour compared with baseline measures, as well as compared with the control group. The result is in line with Galvin et al. (2007), who found significant MCI progress in CI users, following daily computer-based training. This suggests that MCI may be substantially improved also by training that combines playing/singing exercises and listening exercises. The fact that the NH group performed significantly better than the CI listeners, however, indicates that discrimination of melodic direction remains challenging with a CI even after musical training.

\section{Pitch Ranking}

We found a trend toward a higher gain in the ability to rank two pitches among the music group participants compared with the controls. Because it requires discrimination of pitch direction where the base pitch is not fixed, the PR task is considerably more challenging than the MCI, which uses a fixed frequency base. Because PR was not specifically trained, this trend in the music group's progress may represent a generalized effect from the musical training. It is worth noting that although the average end-point scores of the CI users were significantly poorer than those of the $\mathrm{NH}$ group, five music group participants and one control group participant produced scores near the $\mathrm{NH}$ range, thereby correctly identifying interval changes as small as $1 \mathrm{ST}$. This variability indicates an effect of the training, but might also be linked to differences in the preconditions for music listening, such as duration of HL and residual hearing.

\section{Rhythm Discrimination}

Several studies have concluded that perception of rhythm with a CI is close to normal (Gfeller, Woodworth, Robin, Witt, \& Knutson, 1997; Kong et al., 2004; Limb, Molloy, Jiradejvong, \& Braun, 2010). Many of these studies, however, used simple tempo or pattern discrimination tests exhibiting ceiling effects in both CI and $\mathrm{NH}$ groups. In our study, the music group participants improved in their ability to discriminate complex rhythm patterns and 
Table 4

Correlations Between Overall Music Z-Scores and HAG/EPR

\begin{tabular}{|c|c|c|c|c|c|c|c|c|c|c|c|c|}
\hline & \multicolumn{4}{|c|}{ Baseline } & \multicolumn{4}{|c|}{ Midpoint } & \multicolumn{4}{|c|}{ End point } \\
\hline & \multicolumn{2}{|c|}{ HAG } & \multicolumn{2}{|c|}{ EPR } & \multicolumn{2}{|c|}{ HAG } & \multicolumn{2}{|c|}{ EPR } & \multicolumn{2}{|c|}{ HAG } & \multicolumn{2}{|c|}{ EPR } \\
\hline & $r$ & $p$ & $r$ & $p$ & $r$ & $p$ & $r$ & $p$ & $r$ & $p$ & $r$ & $p$ \\
\hline \multicolumn{13}{|l|}{ Music group (MG) } \\
\hline EPR & .35 & .36 & - & - & .72 & $.03^{*}$ & - & - & .76 & $.02^{*}$ & - & - \\
\hline Overall music $z$-scores & .59 & .10 & .13 & .74 & .59 & .09 & .66 & $.049^{*}$ & .62 & .08 & .66 & $.047^{*}$ \\
\hline \multicolumn{13}{|l|}{ Control group (CG) } \\
\hline EPR & .48 & .28 & - & - & -.15 & .74 & - & - & -.24 & .60 & - & - \\
\hline Overall music $z$-scores & .48 & .28 & .01 & .97 & .57 & .19 & -.04 & .92 & .86 & $.01^{*}$ & .04 & .92 \\
\hline \multicolumn{13}{|l|}{ MG and CG pooled } \\
\hline EPR & .34 & .19 & - & - & .19 & .49 & - & - & .22 & .42 & - & - \\
\hline Overall music $z$-scores & .55 & $.03^{*}$ & .09 & .72 & .59 & $.02^{*}$ & .34 & .17 & .61 & $.01^{*}$ & .26 & .30 \\
\hline
\end{tabular}

Note. Correlations between overall music $z$-scores and HAG and EPR scores in the music group, the control group, and music group and control group pooled. HAG = Hagerman sentence test; EPR = emotional prosody recognition test.

* Term significant at alpha $=.05$.

reached end-point performance levels comparable with the $\mathrm{NH}$ group and significantly higher than those of the control group, which is an indication of the effect of training. The finding is encouraging, and evidence of the high accuracy with which current implant technology transmits temporal information. It is assumed that those CI users who successfully listen to music primarily depend on lyrics and rhythm (Gfeller et al., 2008). This implies that enhanced discrimination of rhythm, as a result of training, may assist CI users, in general, when listening to music. Moreover, poor perception of rhythm has been associated with poor perception of syllable stress and dyslexia (Huss, Verney, Fosker, Mead, \& Goswami, 2011; Overy, 2003; Overy, Nicolson, Fawcett, \& Clarke, 2003), and it is possible that training of rhythm, in the long term, could form a beneficial part in auditory-oral therapy, directed not only at adult but also pediatric CI users.

\section{Melodic Discrimination}

Ability to correctly identify pitch direction, as measured in MCI and $\mathrm{PR}$, is a fundamental prerequisite for perception (and production) of melody, and is usually strongly associated with familiar melody recognition in CI listeners (Galvin et al., 2007; Gfeller et al., 2002a; Looi, McDermott, McKay, \& Hickson, 2004). Despite significantly improved identification of melodic contour and a trend toward better pitch discrimination, the average MD skills of the music group participants improved nonsignificantly. However, in contrast to recognition of familiar melodies, as used in the former studies, the MD test used in the present study assessed the comparison of unfamiliar melodies, which is substantially more challenging, loading heavily on working memory, which may be restricted in some CI users (Knutson et al., 1991). Furthermore, the poor progress in MD indicates that for a CI listener, perception of pitch in the context of many pitches is a challenging task. Finally, the test revealed a floor effect, indicating the test was simply too difficult for this purpose.

\section{Language Outcome}

The remarkable progress in the average speech perception observed across all participants regardless of group is in line with findings of previous studies, which showed that most performance gains occur in the first 3 months of use (Ruffin et al., 2007; Spivak \& Waltzman, 1990). Such drastic development after implantation shows not only the efficiency of the CI technology but also the potential of cortical plasticity to reactivate inactive areas in the brain (Petersen, Mortensen, Gjedde, \& Vuust, 2009). Interestingly, our correlation analyses suggested a relationship between speech perception performance and overall music discrimination performance, which could be explained by the necessity of low-level acoustic feature extraction from sounds in both domains (Besson \& Schon, 2001). This, however, is in contrast with Singh, Kong, and Zeng (2009), who, in a sample of adult CI users, found no relationship between melody recognition and phoneme discrimination, and with Gfeller et al. (2008), who found association between speech perception and music perception only when lyrics were present. These findings are consistent with the view that high-level processing of music and language primarily takes place in separate brain modules (Peretz \& Coltheart, 2003).

The absence of a significant effect of the musical training on speech perception and the absence of a correlation between music and speech performance gain indicate that the progress in either domain may take place independently of one another. This is supported by the cases of the five prelingually deaf participants in our study, who, despite moderate progress in their general music perception, either failed to show any improvement or showed only modest speech perception improvement. Thus, in contrast to our hypothesis, we may conclude that there is no transfer effect from enhanced musical discrimination skills onto the linguistic domain in CI users who recently underwent implantation. However, a transfer effect may have been masked by the magnitude of progress found in both study groups, as well as by other confounding variables. First, in the initial phase of CI adaptation, the speech perception progress may be so strongly carried by the effect of daily use that other sources of training may be of lesser significance. Second, all participants followed speech therapy, which may have had substantial influence on the perceptual development. Third, the implant is specifically optimized to effectively facilitate speech perception. Finally, the HAG may have been inadequate in comparing development in the two groups. A ceiling-like effect 
with five of nine music group participants and two of nine control group participants scoring within the 90th percentile, at the endpoint measurement, may have prevented some participants from achieving higher scores.

Both groups significantly improved in their abilities to recognize emotional prosody. However, in contrast to the control group, the major part of the music group's progress occurred in the initial 3-month training period. Furthermore, we found a significant correlation between the overall music $z$-scores and EPR performance in the music group, which was absent in the control group. This suggests that musical training may have not only affected the speed of the EPR progress but also strengthened the link between music discrimination and EPR. The unexpected progress of the control group, in contrast, indicates that because the range of changes in pitch and timing in emotional prosody is much greater than that seen in music, these cues may be more easily identified (Ayotte, Peretz, \& Hyde, 2002). Nevertheless, in line with findings of Xin Luo, Fu, and Galvin (2007), both groups scored significantly below the NH level, which emphasizes that these prosodic cues are particularly challenging to CI listeners and may explain the lack of further progress in the music group.

\section{The Effect of Contralateral Hearing}

The strong negative relationship between use of contralateral HA and overall music and EPR end-point gain implies that combined acoustic and electric hearing did not facilitate progress in music discrimination, or ability to decode emotional prosody. It should be emphasized, however, that some studies have demonstrated significantly improved music perception performance in participants who combined their CI with an HA in their nonimplanted ear (Gfeller et al., 2007; Kong, Stickney, \& Zeng, 2005; Looi, McDermott, McKay, \& Hickson, 2008). Here, a majority of participants used their HAs on a daily basis, but were tested with the HA switched off. Had they been allowed to use their HA during tests, some of these participants may have produced higher music scores. Future studies on music listening with bimodal and bilateral hearing should examine these possible advantages more thoroughly.

One music group participant scored $100 \%$ correct on the final sentence test. This individual adapted fast to the CI and also performed well on all other tests, scoring highest of all in the MD test. Her residual hearing was $>70$ to $80 \mathrm{~dB}$ HL on the contralateral ear and $>90 \mathrm{~dB}$ HL on the implanted ear. With the HA turned off and plugged in, this is not likely to have contributed to her remarkable progress. She enjoys listening to music but has never played an instrument or sung. The best explanation of this extraordinary case may be an unusual high level of motivation.

\section{The Influence of Age on the Benefits of Musical Training}

Age showed a significant negative relationship with overall music gain across all participants. This implies that younger participants had a relatively larger improvement of their general music discrimination skills than older participants. Because age showed no relationship with either overall music performance or HAG and EPR gain, a possible explanation of this finding is that greater cortical plasticity facilitates learning of the more complex discrimination tasks associated with music listening. The finding may also reflect a higher music listening frequency in younger CI recipients than in older ones, as observed by Mirza et al. (2003), or suggest that older persons may require more extensive training, to achieve similar benefit compared with younger adults, as proposed by Driscoll, Oleson, Jiang, and Gfeller (2009).

\section{The Influence of Duration of Deafness on the Benefits of Musical Training}

As expected, duration of profound deafness was predictive of speech perception, meaning that a short period of deafness preimplantation was associated with better speech perception. However, duration of profound deafness was not related to speech perception gain, which suggests that duration of deafness may not necessarily predict speech progress. Surprisingly, no correlation was observed between duration of deafness and overall music or EPR performance. As discussed earlier, this suggests that long-time deafness may not preclude acquisition of aspects of music perception.

\section{Limitations of the Study}

Two music group and three control group participants had a profound prelingual HL, and their performance was at floor in the speech perception test. Although MG 2, MG 8, and CG 4 showed varying degrees of progress, CG 3 and CG 6, for unknown reasons, remained unable to perceive speech throughout the study period. This difference in hearing background make direct comparisons between groups less valid than desired, but has, in contrast, provided interesting insight into the music perception and the potential effect of training for this relatively small group of CI recipients.

All participants in the music group completed the training program. This positive result may partly be due to the personal coaching aspect of the training program, and we acknowledge that such specialized one-to-one contact in itself may provide a psychological benefit. Because the control group did not receive a similar enriching experience, this may give rise to some concern about the design of the study and the comparability of the development in the two groups. In that respect, it is worth noting that the benefits were observed directly in the area of training (i.e., music) and not outside this area (i.e., speech tests). Thus, the potential benefit does not seem to have had a major influence on the results.

The audiovisual training applications, in general, proved valid for supplementary home training. However, according to verbal reports, the amount of time that music group participants spent on home practice was varied. Although it would have been preferable to hold this parameter constant, the variability reflects the differential employment and family background found among the participants in the music group.

\section{The Music-Training Program}

The music-training program was not formally evaluated, but the participants, in general, gave positive feedback. MG 5 and MG 9 were interviewed about their experiences with the program. MG 5 commented, "The activities have been exciting and amusing, and the recurrent measurements of my progress have been tremendously motivating. The opportunity to sing out loud and be guided 
in my performance has been wonderful, and learning to accompany myself with chords on the piano was beyond my wildest imagination." MG 9, who was interviewed on national radio, commented, "The music listening exercises have helped me a lot. It has supported my ability to segregate sounds and focus my listening - but it has taken some time." About her experience with singing, she added, "I have always been incredibly shy to sing at birthdays and Christmas. Even with my family I never felt like singing along. This year, maybe I'll sing a bit louder."

Surprisingly, the majority of MG participants found singing particularly fruitful and profitable, despite the obvious challenges of intonation. Of course, singing comprises all the important elements of ear training; it involves simultaneous production and perception of sound, it features pitch, timing, and timbre, and, more importantly, has a linguistic_lyrical dimension. Furthermore, we observed that several participants spoke and sang in strikingly soft voices, probably owing to long-time insecurity about the loudness of their own voice. Having received their new electrical "ear," these CI listeners were getting acquainted with their voice anew, and the different vocal exercises in many cases were beneficial in gaining more volume and improved voice quality, also in the context of speaking. A similar experience has been found in a study that used actor vocal training (Holt \& Dowell, 2011).

\section{Perspectives}

Music enjoyment through an implant is not just a function of perceptual accuracy. Many factors such as the quality of sound, acoustic environment, familiarity with the music, and, in particular, the structural features and style of music, influence music enjoyment. However, for the majority of implant users, who find music "hard to follow" or unpleasant, introduction to the key features of music and training of the ability to discriminate different musical sounds, as examined in the present study, may be helpful in the struggle for a higher music satisfaction. Even sparse improvements of music enjoyment may have considerable positive influence on the quality of life of CI users (Lassaletta et al., 2007). Future research should elucidate the association between these factors.

Although the effect of music training on speech perception was not evident, it may be that such training, if given at a later stage in the CI adaptation process once speech perception has stabilized, might provide further support, especially in the recognition of emotional prosody. Future research should examine this potential benefit.

\section{Conclusion}

This study measured the progress of musical and linguistic skills in adults with CIs who recently underwent implantation, following musical training or no musical training. We conclude that musical ear training, based on one-to-one training, active music-making methods, and listening exercises, has a potential as a motivating and efficient method to improve the overall perception of music in CI users. In particular, discrimination of timbre and melodic contour can be enhanced, thereby providing improved prerequisites for fundamental aspects of music listening. Furthermore, perception of rhythm is positively affected by training and can even reach
NH levels, which may benefit music understanding, in general, and some aspects of speech perception. Perception of speech may not necessarily benefit from musical ear training in this initial phase of CI adaptation, whereas perception of emotional prosody may progress more quickly and associate with musical skills. Despite its obviously challenging nature, singing might be fruitful and profitable to some CI listeners, as a means of training pitch perception, articulation, and phrasing. Thus, the proposed musical ear-training program could form a valuable complementary method of auditory rehabilitation, and, in the long term, contribute to an improved general quality of life in CI users. The great compliance of the participants indicates that such measures could be relatively easily implemented.

\section{References}

Altenmüller, E. (2008). Neurology of musical performance. Clinical Medicine (London, England), 8, 410-413.

Ayotte, J., Peretz, I, \& Hyde, K. (2002). Congenital amusia: A group study of adults afflicted with a music-specific disorder. Brain, $125(\mathrm{Pt} 2)$, 238-251. doi:10.1093/brain/awf028

Besson, M., \& SchöN, D. (2001). Comparison between language and music. Annals of the New York Academy of Sciences, 930, 232-258. doi:10.1111/j.1749-6632.2001.tb05736.x

Besson, M., Schön, D., Moreno, S., Santos, A., \& Magne, C. (2007). Influence of musical expertise and musical training on pitch processing in music and language. Restorative Neurology and Neuroscience, 25, 399-410.

Büchler, M. (2008). The Zurich Music Test Battery [Software package]. ENT Dept, Exp. Audiology, University Hospital, Zurich, Switzerland.

Cooper, W. B., Tobey, E., \& Loizou, P. C. (2008). Music perception by cochlear implant and normal hearing listeners as measured by the Montreal Battery for Evaluation of Amusia. Ear and Hearing, 29, 618-626. doi:10.1097/AUD.0b013e318174e787

Cosetti, M. K., \& Waltzman, S. B. (2012). Outcomes in cochlear implantation: Variables affecting performance in adults and children. Otolaryngologic Clinics of North America, 45, 155-171. doi:10.1016/j.otc .2011 .08 .023

Driscoll, V. D., Oleson, J., Jiang, D., \& Gfeller, K. (2009). Effects of training on recognition of musical instruments presented through cochlear implant simulations. Journal of the American Academy of Audiology, 20, 71-82. doi:10.3766/jaaa.20.1.7

Engberg, I. S., \& Hansen, A. V. (1996). Danish Emotional Speech Database (DES). Center for PersonKommunikation (CPK), Aalborg University, Denmark.

Friesen, L. M., Shannon, R. V., Baskent, D., \& Wang, X. (2001). Speech recognition in noise as a function of the number of spectral channels: Comparison of acoustic hearing and cochlear implants. Journal of the Acoustical Society of America, 110, 1150-1163. doi:10.1121/1.1381538

Fu, Q.-J., \& Galvin, J. J. (2008). Maximizing cochlear implant patients' performance with advanced speech training procedures. Hearing Research, 242, 198-208. doi:10.1016/j.heares.2007.11.010

Fujita, S., \& Ito, J. (1999). Ability of nucleus cochlear implantees to recognize music. The Annals of Otology, Rhinology, and Laryngology, 108(7 Pt 1), 634-640.

Galvin, J. J., Fu, Q.-J., \& Nogaki, G. (2007). Melodic contour identification by cochlear implant listeners. Ear and Hearing, 28, 302-319. doi: 10.1097/01.aud.0000261689.35445.20

Gfeller, K., Christ, A., Knutson, J. F., Witt, S., Murray, K. T., \& Tyler, R. S. (2000). Musical backgrounds, listening habits, and aesthetic enjoyment of adult cochlear implant recipients. Journal of the American Academy of Audiology, 11, 390-406. 
Gfeller, K., \& Lansing, C. R. (1991). Melodic, rhythmic, and timbral perception of adult cochlear implant users. Journal of Speech and Hearing Research, 34, 916-920.

Gfeller, K., Oleson, J., Knutson, J. F., Breheny, P., Driscoll, V., \& Olszewski, C. (2008). Multivariate predictors of music perception and appraisal by adult cochlear implant users. Journal of the American Academy of Audiology, 19, 120-134. doi:10.3766/jaaa.19.2.3

Gfeller, K., Olszewski, C., Rychener, M., Sena, K., Knutson, J. F., Witt, S., \& Macpherson, B. (2005). Recognition of "real-world" musical excerpts by cochlear implant recipients and normal-hearing adults. Ear and Hearing, 26, 237-250. doi:10.1097/00003446-200506000-00001

Gfeller, K. E., Olszewski, C., Turner, C., Gantz, B., \& Oleson, J. (2006). Music perception with cochlear implants and residual hearing. Audiology and Neurotology, 11, 12-15. doi:10.1159/000095608

Gfeller, K., Turner, C., Mehr, M., Woodworth, G., Fearn, R., Knutson, J. F., . . Stordahl, J. (2002a). Recognition of familiar melodies by adult cochlear implant recipients and normal-hearing adults. Cochlear Implants International, 3, 29-53. doi:10.1002/cii.50

Gfeller, K., Turner, C., Oleson, J., Zhang, X., Gantz, B., Froman, R., \& Olszewski, C. (2007). Accuracy of cochlear implant recipients on pitch perception, melody recognition, and speech reception in noise. Ear and Hearing, 28, 412-423. doi:10.1097/AUD.0b013e3180479318

Gfeller, K., Witt, S., Adamek, M., Mehr, M., Rogers, J., Stordahl, J., \& Ringgenberg, S. (2002b). Effects of training on timbre recognition and appraisal by postlingually deafened cochlear implant recipients. Journal of the American Academy of Audiology, 13, 132-145.

Gfeller, K., Witt, S., Stordahl, J., Mehr, M., \& Woodworth, G. (2000). The effects of training on melody recognition and appraisal by adult cochlear implants recipients. Journal of the Academy of Rehabilitative Audiology, $33,115-138$

Gfeller, K., Witt, S., Woodworth, G., Mehr, M. A., \& Knutson, J. (2002). Effects of frequency, instrumental family, and cochlear implant type on timbre recognition and appraisal. The Annals of Otology, Rhinology, and Laryngology, 111, 349-356.

Gfeller, K., Woodworth, G., Robin, D. A., Witt, S., \& Knutson, J. F. (1997). Perception of rhythmic and sequential pitch patterns by normally hearing adults and adult cochlear implant users. Ear \& Hearing, 18, 252-260. doi:10.1097/00003446-199706000-00008

Hansen, M., Wallentin, M., \& Vuust, P. (2012). Working memory and musical competence of musicians and non-musicians. Psychology of Music. doi:10.1177/0305735612452186

Hintze, J. (2012). NCSS 8. Kaysville, UT: NCSS, LLC. www.ncss.com

Holt, C. M., \& Dowell, R. C. (2011). Actor vocal training for the habilitation of speech in adolescent users of cochlear implants. Journal of Deaf Studies and Deaf Education, 16, 140-151. doi:10.1093/deafed/ enq033

Huss, M., Verney, J. P., Fosker, T., Mead, N., \& Goswami, U. (2011). Music, rhythm, rise time perception and developmental dyslexia: Perception of musical meter predicts reading and phonology. Cortex, 47, 674-689. doi:10.1016/j.cortex.2010.07.010

Juslin, P. N., \& Laukka, P. (2003). Communication of emotions in vocal expression and music performance: Different channels, same code? Psychological Bulletin, 129, 770-814. doi:10.1037/0033-2909.129.5 .770

Knutson, J. F., Hinrichs, J. V., Tyler, R. S., Gantz, B. J., Schartz, H. A., \& Woodworth, G. (1991). Psychological predictors of audiological outcomes of multichannel cochlear implants: Preliminary findings. The Annals of Otology, Rhinology, and Laryngology, 100, 817-822.

Koelsch, S., Schröger, E., \& Tervaniemi, M. (1999). Superior pre-attentive auditory processing in musicians. NeuroReport, 10, 1309-1313. doi: 10.1097/00001756-199904260-00029

Kong, Y.-Y., Cruz, R., Jones, J. A., \& Zeng, F.-G. (2004). Music perception with temporal cues in acoustic and electric hearing. Ear and Hearing, 25, 173-185. doi:10.1097/01.AUD.0000120365.97792.2F
Kong, Y.-Y., Stickney, G. S., \& Zeng, F.-G. (2005). Speech and melody recognition in binaurally combined acoustic and electric hearing. The Journal of the Acoustical Society of America, 117(3 Pt 1), 1351-1361. doi:10.1121/1.1857526

Lai, W. (2000). MACarena, MAC (Minimal Auditory Capability) test battery. Zürich, Switzerland: University Hospital.

Lassaletta, L., Castro, A., Bastarrica, M., Perez-Mora, R., Herran, B., Sanz, L., . . Gavilán, J. (2008). Changes in listening habits and quality of musical sound after cochlear implantation. Otolaryngology Head and Neck Surgery, 138, 363-367. doi:S0194-5998(07)01971-7

Lassaletta, L., Castro, A., Bastarrica, M., Pérez-Mora, R., Madero, R., De Sarriá, J., \& Gavilán, J. (2007). Does music perception have an impact on quality of life following cochlear implantation? Acta Otolaryngologica, 127, 682-686. doi:10.1080/00016480601002112

Leal, M. C., Shin, Y. J., Laborde, M.-L., Calmels, M.-N., Verges, S., Lugardon, S., . . Fraysse, B. (2003). Music perception in adult cochlear implant recipients. Acta Oto-Laryngologica, 123, 826-835. doi 10.1080/00016480310000386

Lee, H. J., Giraud, A. L., Kang, E., Oh, S. H., Kang, H., Kim, C. S.,\& Lee, D. S. (2007). Cortical activity at rest predicts cochlear implantation outcome. Cerebral Cortex, 17, 909-917. doi:10.1093/cercor/bhl001

Levitin, D., \& Menon, V. (2003). Musical structure is processed in "language" areas of the brain: A possible role for Brodmann area 47 in temporal coherence. NeuroImage, 20, 2142-2152. doi:10.1016/j neuroimage.2003.08.016.

Limb, C. J., Molloy, A. T., Jiradejvong, P., \& Braun, A. R. (2010) Auditory cortical activity during cochlear implant-mediated perception of spoken language, melody, and rhythm. Journal of the Association for Research in Otolaryngology, 11, 133-143. doi:10.1007/s10162-0090184-9

Loizou, P. C. (1999). Introduction to cochlear implants. IEEE Engineering in Medicine and Biology Magazine, 18, 32-42. doi:10.1109/51.740962

Looi, V., McDermott, H., McKay, C., \& Hickson, L. (2004). Pitch discrimination and melody recognition by cochlear implant users. International Congress Series, 1273, 197-200. doi:10.1016/j.ics.2004.08.038

Looi, V., McDermott, H., McKay, C., \& Hickson, L. (2008). Music perception of cochlear implant users compared with that of hearing aid users. Ear and Hearing, 29, 421-434. doi:10.1097/AUD $.0 \mathrm{~b} 013 \mathrm{e} 31816 \mathrm{a} 0 \mathrm{~d} 0 \mathrm{~b}$

Looi, V., \& She, J. (2010). Music perception of cochlear implant users: A questionnaire, and its implications for a music training program. International Journal of Audiology, 49, 116-128. doi:10.3109/ 14992020903405987

Xin Luo, L., Fu, Q.-J., \& Galvin, J. J. (2007). Vocal emotion recognition by normal-hearing listeners and cochlear implant users. Trends in Amplification, 11 301-315. doi:10.1177/1084713807305301

McDermott, H. J. (2004). Music perception with cochlear implants: A review. Trends in Amplification, 8, 49-82. doi:10.1177/ 108471380400800203

McDermott, H. J., \& Looi, V. (2004). Perception of complex signals, including musical sounds, with cochlear implants. International Congress Series, 1273, 201-204. doi:10.1016/j.ics.2004.08.034

Mirza, S., Douglas, S., Lindsey, P., Hildreth, T., \& Hawthorne, M. (2003). Appreciation of music in adult patients with cochlear implants: A patient questionnaire. Cochlear Implants International, 4, 85-95. doi: 10.1002/cii.68

Näätänen, R., Gaillard, A. W. K., \& Mäntysalo, S. (1978). Early selectiveattention effect on evoked potential reinterpreted. Acta Psychologica, 42, 313-329. doi:10.1016/0001-6918(78)90006-9

Näätänen, R., Tervaniemi, M., Sussman, E., Paavilainen, P., \& Winkler, I. (2001). "Primitive intelligence" in the auditory cortex. Trends in Neurosciences, 24, 283-288. doi:10.1016/S0166-2236(00)01790-2

Olszewski, C., Gfeller, K., Froman, R., Stordahl, J., \& Tomblin, B. (2005). Familiar melody recognition by children and adults using cochlear 
implants and normal hearing children. Cochlear Implants International, 6, 123-140. doi:10.1002/cii.5

Overy, K. (2003). Dyslexia and music. From timing deficits to musical intervention. Annals of the New York Academy of Sciences, 999, 497505. doi:10.1196/annals. 1284.060

Overy, K., Nicolson, R. I., Fawcett, A. J., \& Clarke, E. F. (2003). Dyslexia and music: Measuring musical timing skills. Dyslexia, 9, 18-36. doi: $10.1002 /$ dys. 233

Pantev, C., Oostenveld, R., Engelien, A., Ross, B., Roberts, L. E., \& Hoke, M. (1998). Increased auditory cortical representation in musicians. $\mathrm{Na}$ ture, 392, 811-814. doi:10.1038/33918

Parbery-Clark, A., Skoe, E., Lam, C., \& Kraus, N. (2009). Musician enhancement for speech-in-noise. Ear and Hearing, 30, 653-661. doi: 10.1097/AUD.0b013e3181b412e9

Peretz, I., \& Coltheart, M. (2003). Modularity of music processing. Nature Neuroscience, 6, 688-691. doi:10.1038/nn1083

Petersen, B., Mortensen, M. V., Gjedde, A., \& Vuust, P. (2009). Reestablishing speech understanding through musical ear training after cochlear implantation: A study of the potential cortical plasticity in the brain. Annals of the New York Academy of Sciences, 1169, 437-440. doi: 10.1111/j.1749-6632.2009.04796.x

Pressnitzer, D., Bestel, J., \& Fraysse, B. (2005). Music to electric ears: pitch and timbre perception by cochlear implant patients. Annals of the New York Academy of Sciences, 1060, 343-345. doi:10.1196/annals .1360 .050

Qin, M. K., \& Oxenham, A. J. (2003). Effects of simulated cochlearimplant processing on speech reception in fluctuating maskers. Journal of the Acoustical Society of America, 114, 446-454. doi:10.1121/1 .1579009

Ruffin, C. V., Tyler, R. S., Witt, S. A., Dunn, C. C., Gantz, B. J., \& Rubinstein, J. T. (2007). Long-term performance of clarion 1.0 cochlear implant users. The Laryngoscope, 117, 1183-1190. doi:10.1097/MLG 0b013e318058191a

Singh, S., Kong, Y.-Y., \& Zeng, F.-G. (2009). Cochlear implant melody recognition as a function of melody frequency range, harmonicity, and number of electrodes. Ear and Hearing, 30, 160-168. doi:10.1097/AUD $.0 \mathrm{~b} 013 \mathrm{e} 31819342 \mathrm{~b} 9$

Spivak, L. G., \& Waltzman, S. B. (1990). Performance of cochlear implant patients as a function of time. Journal of Speech and Hearing Research, $33,511-519$.

Summerfield, A. Q., \& Marshall, D. H. (1995). Preoperative predictors of outcomes from cochlear implantation in adults: Performance and quality of life. The Annals of Otology, Rhinology \& Laryngology Supplement, 166, 105-108.

Thompson, W. F., Schellenberg, E. G., \& Husain, G. (2003). Perceiving prosody in speech. Effects of music lessons. Annals of the New York Academy of Sciences, 999, 530-532. doi:10.1196/annals.1284.067

Vongphoe, M., \& Zeng, F.-G. (2005). Speaker recognition with temporal cues in acoustic and electric hearing. The Journal of the Acoustical Society of America, 118, 1055-1061. doi:10.1121/1.1944507

Vuust, P., Pallesen, K. J., Bailey, C., van Zuijen, T. L., Gjedde, A., Roepstorff, A., \& Østergaard, L. (2005). To musicians, the message is in the meter. Neuroimage, 24, 560-564. doi:10.1016/j.neuroimage.2004.08 .039

Vuust, P., \& Roepstorff, A. (2008). Listen up! Polyrhythms in brain and music. Cognitive Semiotics, 2008, 134-158. doi:10.3726/81606_134

Vuust, P., Roepstorff, A., Wallentin, M., Mouridsen, K., \& Østergaard, L. (2006) It don't mean a thing .... NeuroImage, 31, 832-841. doi: 10.1016/j.neuroimage. 2005.12.037

Wallentin, M., Nielsen, A. H., Friis-Olivarius, M., Vuust, C., \& Vuust, P. (2010). The Musical Ear Test, a new reliable test for measuring musical competence. Learning and Individual Differences, 20, 188-196. doi: 10.1016/j.lindif.2010.02.004

Waltzman, S. B., Fisher, S. G., Niparko, J. K., \& Cohen, N. L. (1995) Predictors of postoperative performance with cochlear implants. The Annals of Otology, Rhinology \& Laryngology Supplement, 165, 15-18.

Wilson, B. S., \& Dorman, M. F. (2007). The surprising performance of present-day cochlear implants. IEEE Transactions on Biomedical Engineering, 54(6 Pt 1), 969-972. doi:10.1109/TBME.2007.893505 
Appendix A

Individual Music Test Scores
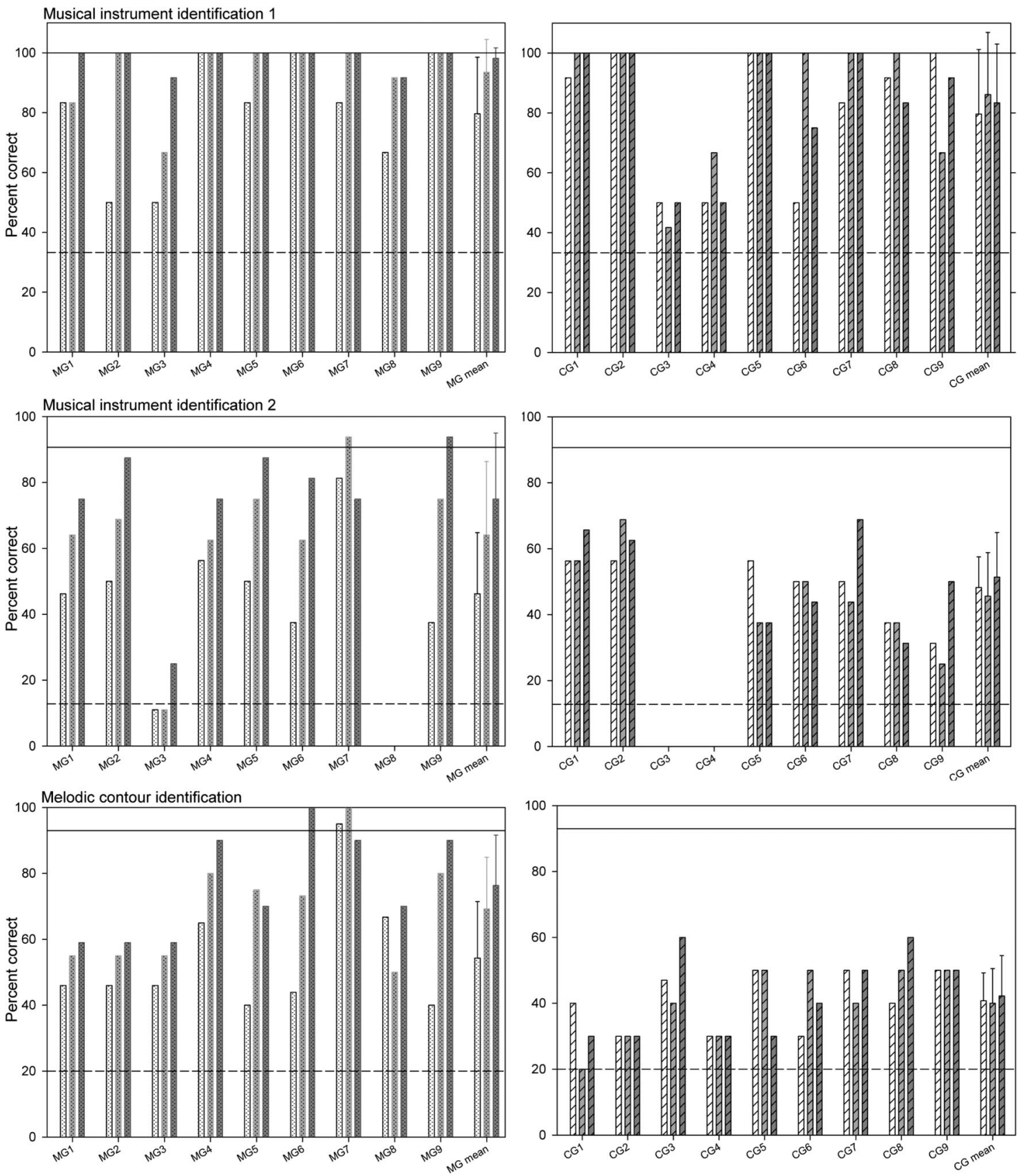

Figure A1. Individual and mean performance scores for the music group (MG; left) and the control group (CG; right) at baseline, midpoint, and end point in the six music tests. Dashed line $=$ chance level; solid line $=\mathrm{NH}$ performance level. Missing scores are due to the participant's inability to complete the tests. 

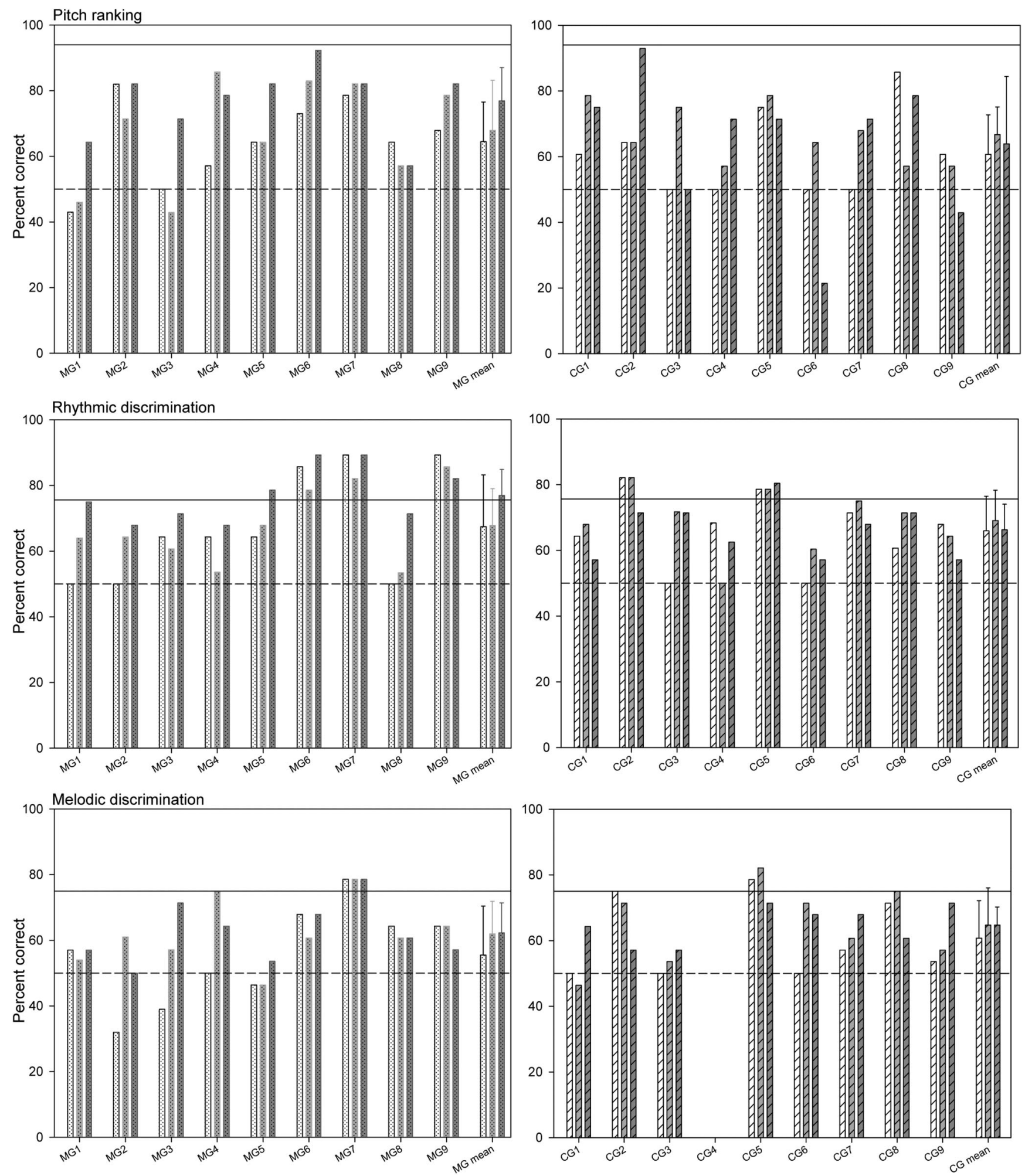

Figure A1. (Continued) 
Appendix B

Individual Speech Test Scores
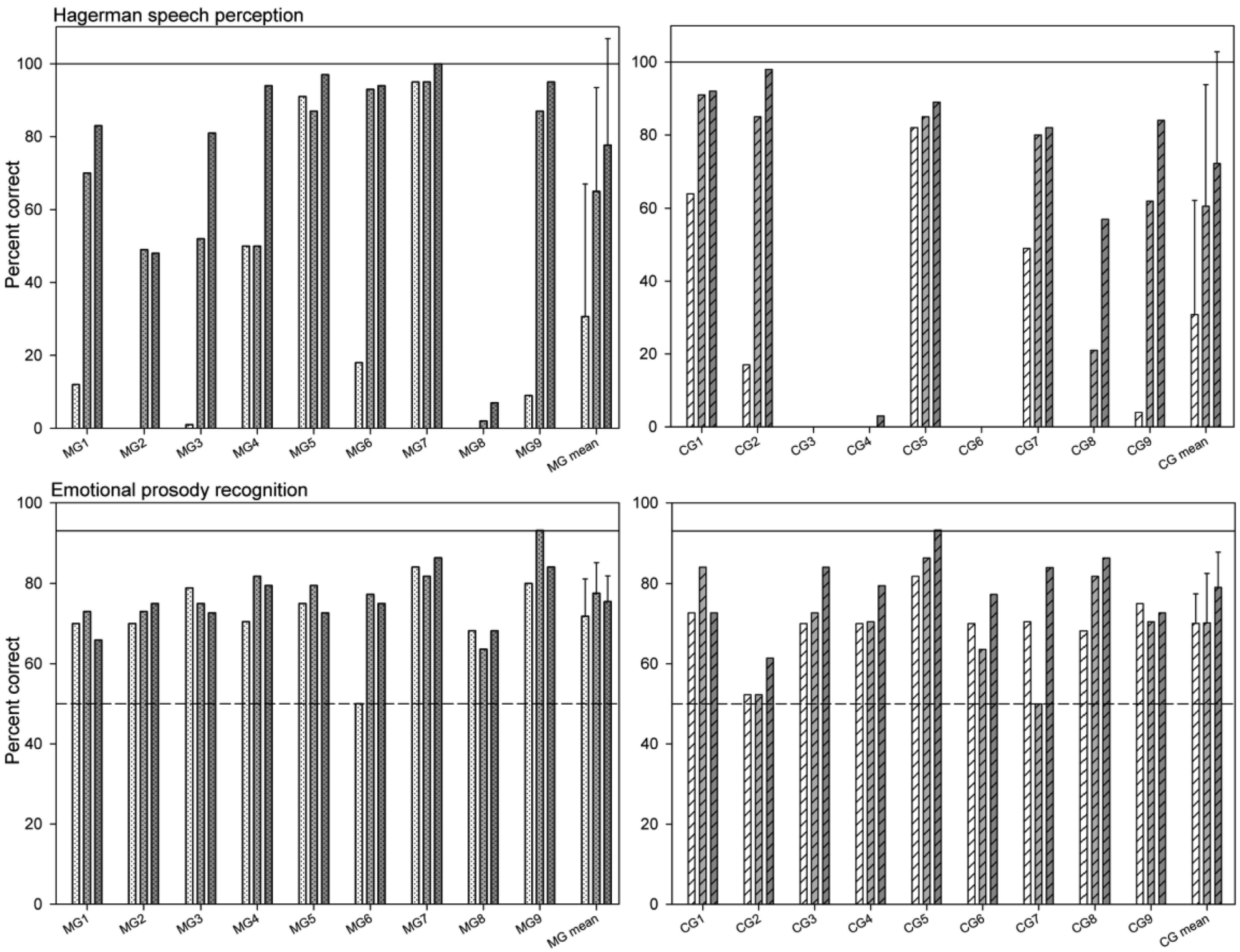

Figure B1. Individual and mean performance scores for the music group (MG; left) and the control group (CG; right) at baseline, midpoint, and end point in the two speech tests. Dashed line = chance level; solid line $=\mathrm{NH}$ performance level. Missing bars are due to 0 point scores.

Received June 26, 2012

Revision received November 5, 2012 